\title{
Cold sintering of microwave dielectric ceramics and devices
}

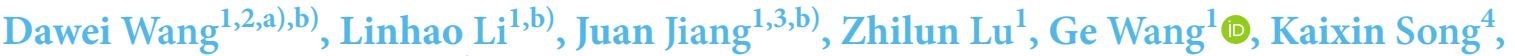 \\ Di Zhou ${ }^{5}$, Ian M. Reaney, a) \\ ${ }^{1}$ Department of Materials Science and Engineering, University of Sheffield, Sheffield S1 3JD, UK \\ ${ }^{2}$ Shenzhen Institute of Advanced Electronic Materials, Shenzhen Institutes of Advanced Technology, Chinese Academy of Sciences, Shenzhen 518055, \\ China \\ ${ }^{3}$ Faculty of Materials Science and Engineering, Hubei University, Wuhan 430062, China \\ ${ }^{4}$ College of Electronics Information, Hangzhou Dianzi University, Hangzhou 310018, China \\ ${ }^{5}$ Electronic Materials Research Laboratory, Key Laboratory of the Ministry of Education \& International Center for Dielectric Research, School \\ of Electronic Science and Engineering, Xian Jiaotong University, Xian 710049, Shaanxi, China \\ a) Address all correspondence to these authors.e-mails: wangdawei102@gmail.com; i.m.reaney@sheffield.ac.uk \\ b) These authors contributed equally to this work.
}

Received: 2 November 2020; accepted: 3 December 2020; published online: 13 January 2021

Microwave (MW) dielectric ceramics are used in numerous electronic components for modern wireless communication systems, including antennas, resonators, capacitors and filters. However, to date, $\mathrm{MW}$ ceramics are manufactured by an energy-intensive, conventional high-temperature $\left(>1000^{\circ} \mathrm{C}\right)$ sintering technology and thus cannot be co-sintered with low melting point and base electrodes (Ag, Al, etc., $\left.<1000^{\circ} \mathrm{C}\right)$, nor directly integrated with polymers $\left(<200^{\circ} \mathrm{C}\right)$. Cold sintering is able to densify ceramics at $<200^{\circ} \mathrm{C}$ via a combination of external pressure and a transient liquid phase, reducing the energy consumed and facilitating greater integration with dissimilar materials. This review outlines the basics of MW ceramics alongside the mechanism of cold sintering. Recent developments in cold sintering of MW ceramics, composites and devices are described, emphasizing new materials and progress towards component/device fabrication. Future prospects and critical issues for advancing cold-sintered MW materials and devices, such as unclear mechanism, low $Q \times f$ values and poor mechanical properties, are discussed.

\section{Introduction}

In this review, we present a brief introduction to microwave (MW) ceramics alongside an overview of the mechanisms and state-of-the-art in cold sintering. Subsequently, the review focuses on recent developments in cold sintering MW materials and devices, emphasizing new materials and progress towards component/device fabrication. Finally, the future prospects and critical issues for cold-sintered MW materials and devices are discussed.

\section{Microwave ceramics}

MW dielectrics play important roles in the Internet of Things (IoT), fifth-generation (5G) mobile communication technology and global navigation satellite systems (GNSS), as filters, resonators, antennas and substrates $[1,2]$. The three selective parameters for MW dielectric materials are relative permittivity $\left(\varepsilon_{r}\right)$, quality factor $(Q$, often multiplied by the resonant frequency, $f_{0}$, to give a material constant $\left.Q \times f\right)$ and the temperature coefficient of resonant frequency (TCF or $\tau_{f}$ ).

In conventional electrical circuits, $\varepsilon_{r}$ defines the energy storage capacity of a material when a potential is applied. In the context of MW ceramics however, it is a measure of the interaction of the electromagnetic (EM) wave with the phonon modes of the crystal structure. Generally speaking, the higher the ionic polarizability of the ions within a crystal structure, the larger the value of $\varepsilon_{r}$ at MW frequencies. When MWs travel in a dielectric medium, the wavelength is inversely proportional to the $\sqrt{\varepsilon_{r}}$, according to the equation [2]:

$$
\lambda_{d}=\frac{\lambda_{0}}{\sqrt{\varepsilon_{r}}}=\frac{c}{v \sqrt{\varepsilon_{r}}},
$$


where $\lambda_{d}$ and $\lambda_{0}$ is the wavelength in the dielectric and vacuum, respectively, $c$ is the speed of light and $v$ is frequency. At $f_{0}, v=f_{0}$ and $\lambda_{d}$ is approximately the diameter of the resonating body $(D)$, depending on the resonant mode, such that $[1,2]$

$$
f_{0} \approx \frac{c}{D \sqrt{\varepsilon_{r}}}
$$

Circuit miniaturization for low-frequency applications (2-6 GHz), therefore, requires larger $\varepsilon_{r}$, whereas higher working frequencies (e.g. mm-wave communication) need smaller values. For $4 \mathrm{G}$ and the current generation of $5 \mathrm{G}(2-6 \mathrm{GHz})$ telecommunications, ceramics with medium $\varepsilon_{r}\left(20<\varepsilon_{r}<50\right)$ are typically used for resonators and filters in mobile phone networks (e.g. base stations) [1,2]. As the $5 \mathrm{G}$ network expands however, $\mathrm{mm}$-wave technology will dominate and lower values of $\varepsilon_{r}$ are required with ultralow loss $(Q \times f>100,000 \mathrm{GHz})$.

$Q$ is the reciprocal of the dielectric loss $(\tan \delta)$ and indicates the quantitative dissipation of the electrical energy within a dielectric. In a MW ceramic, it is a function of the width of the resonant peak, measured at $3 \mathrm{~dB}$ below peak height $\left(\Delta f_{0}\right)$ and is given by $f_{0} / \Delta f_{0}$. $\tan \delta$ is the summation of intrinsic and extrinsic losses; intrinsic losses relate to the crystal structure and are described by the interaction of the phonons with the EM field and define the lower limit of $\tan \delta$ and the upper limit of $Q$ in a defect-free single crystal, whereas extrinsic losses are associated with imperfections in the crystal lattice such as impurities, defects, grain boundaries, pores, microcracks, order-disorder, random crystallite orientation, dislocations, vacancies and dopant atoms $[1,2]$. Extrinsic losses can be eliminated or minimized by optimizing material processing. Generally speaking, $Q$ linearly decreases with increasing frequency [1].

The TCF or $\tau_{f}$ indicates the thermal stability of a resonating body and describes the drift of $f_{0}$ as a function of temperature. It is given by [1]

$$
\tau_{f}=-\left(1 / 2 \tau_{\varepsilon}+\alpha_{L}\right),
$$

where $\tau_{\varepsilon}$ and $\alpha_{L}$ are the temperature coefficient of $\varepsilon_{r}$ and the linear expansion coefficient, respectively.

For base stations, unmetallized ceramics are used within cavities as filters and resonators and are required to have $\tau_{f}= \pm 1 \mathrm{ppm} /{ }^{\circ} \mathrm{C}$, ultra-high $Q \times f(>40,000 \mathrm{GHz})$ and $5<\tau_{r}<50$ depending on the operating frequency. For antennas and radio frequency $(\mathrm{RF})$ substrates which typically have surface metallizations, $\tau_{\mathrm{f}}\left( \pm 10 \mathrm{ppm} /{ }^{\circ} \mathrm{C}\right)$ is relaxed with lower values of $Q \times f$ acceptable. $\tau_{r}$ depends on the application but rarely exceeds 100 .

MW ceramics used in co-fired waveguide circuits are divided into four classifications depending on sintering temperature [3]: high-temperature co-fired ceramics (HTCCs, $>1000^{\circ} \mathrm{C}$ ), low-temperature co-fired ceramics (LTCCs, 700-1000 ${ }^{\circ} \mathrm{C}$ ), ultralow-temperature co-fired ceramics (ULTCCs, $400-700^{\circ} \mathrm{C}$ ) and cold-sintered co-fired ceramics (CSCCs, $<200^{\circ} \mathrm{C}$ ). HTCCs $[4,5]$ are typically complex perovskites $[6,7]$, barium titanates
[8], niobates $[9,10]$, silicates $[11-13]$, which cannot be co-fired with base-metal or low melting temperature electrodes (e.g. $\mathrm{Ag}, \mathrm{Cu}, \mathrm{Al}$ ) and whose manufacture is energy intensive [14]. Further miniaturization and integration of MW devices have driven the development of LTCCs and ULTCCs, which may be co-fired with base-metal electrodes without melting and interaction [15-20]. The family of LTCCs and ULTCCs mainly includes glass-ceramics [21-23], tellurates [24, 25], molybdates [26-31], vanadates [32-35], tungstates [36-38] and borates [39-41].

Despite recent advances, the sintering temperatures of LTCCs and ULTCCs are still much higher than can be withstood by a polymer-based printed circuit boards ( $\mathrm{PCBs}<200^{\circ} \mathrm{C}$ ), which inhibits the development of integrated, directly packaged RF devices and systems. CSCCs are a series of ceramics or ceramic composites that can be densified at ultralow temperatures $<200{ }^{\circ} \mathrm{C}$ by the cold sintering process (CSP) [3, 42-49], which enables not only co-firing with base-metal electrodes [3, 50, 51] but also PCBs [52] and polymers [43, 53]. Along with CSCCs for RF applications, cold sintering has also been employed to densify ferroelectrics [54-58], piezoelectrics [59-63], thermoelectrics [64], semiconductors [65-70], electrolytes [71-75], cathodes [76, 77] and oxides [78-82], which are widely used in many applications, Fig. 1.

\section{Cold sintering}

MW ceramics are discussed in detail in section "Microwave Dielectric Materials and Devices by Cold Sintering" but here we present a brief overview of a broader range of functional ceramics that have been shown to cold sinter, alongside a detailed description of the process and its mechanism.

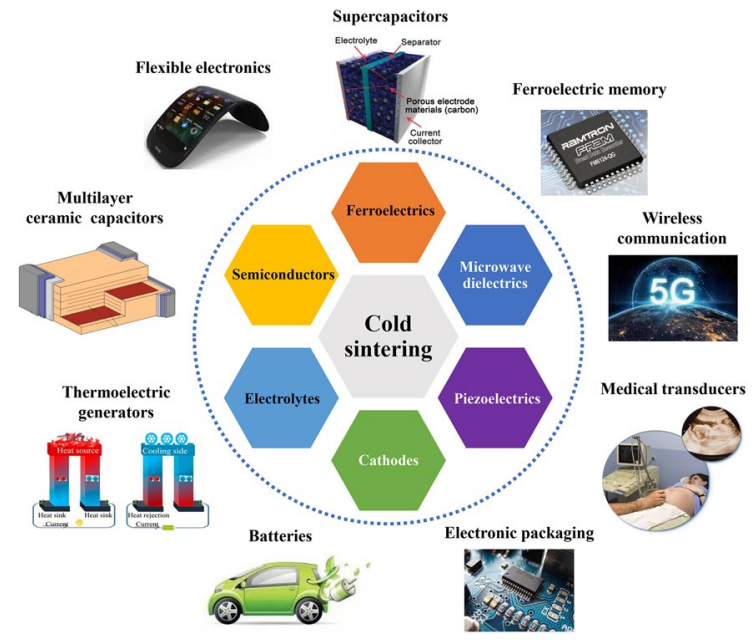

Figure 1: Materials and applications of cold sintering. (Some inset pictures are reprinted with permission from Refs. [83-86]). 


\section{Overview of cold sintering of functional ceramics}

Guo et al. [58] demonstrated that ferroelectric $\mathrm{BaTiO}_{3}$ (BT) ceramics could be densified (relative density, $\rho_{r} \sim 93 \%$ ) at $180{ }^{\circ} \mathrm{C}$ with the help of $\mathrm{Ba}(\mathrm{OH})_{2} / \mathrm{TiO}_{2}$ suspension, which was further increased to $95 \%$ after post-annealing treatment. More recently, dense BT nanoceramics $\left(\rho_{r} \sim 92-95 \%\right.$, grain size $\left.\sim 75-150 \mathrm{~nm}\right)$ were successfully cold sintered in a single step at $300{ }^{\circ} \mathrm{C}$ for $12 \mathrm{~h}$ at $520 \mathrm{MPa}$ with the aid of a molten hydroxide flux $(\mathrm{NaOH}: \mathrm{KOH}=1: 1)$ [55]. Piezoelectric ceramics, such as lead zirconate titanate $\left(\mathrm{Pb}(\mathrm{Zr}, \mathrm{Ti}) \mathrm{O}_{3}, \mathrm{PZT}\right)$, potassium-sodium niobate $\left(\mathrm{K}_{0.5} \mathrm{Na}_{0.5} \mathrm{NbO}_{3}, \mathrm{KNN}\right)$ and sodium bismuth titanate $\left(\mathrm{Na}_{0.5} \mathrm{Bi}_{0.5} \mathrm{TiO}_{3}\right)$, have been successfully densified by cold sintering with the help of transient liquid-phase $\left(\mathrm{Pb}\left(\mathrm{NO}_{3}\right)_{2}\right.$ solution for PZT, $\mathrm{NaCl}$ aqueous solution for $\mathrm{KNN}$ and $\mathrm{Bi}\left(\mathrm{NO}_{3}\right)_{3} /$ $\mathrm{NaOH} / \mathrm{TiO}_{2}$ suspension for NBT [59-63]. Semiconductor $\mathrm{V}_{2} \mathrm{O}_{5}$ as well as $\mathrm{V}_{2} \mathrm{O}_{5}$-poly(3,4-ethylenedioxythiophene) poly(styrene sulfonate) (PEDOT:PSS) composites have been cold sintered at $120^{\circ} \mathrm{C}$ [66]; the electrical conductivity $\left(4.8 \times 10^{-4} \mathrm{~S} / \mathrm{cm}\right.$ at $\left.25^{\circ} \mathrm{C}\right)$, activation energy $\left(0.25 \mathrm{eV}\right.$ at $\left.25^{\circ} \mathrm{C}\right)$ and Seebeck coefficient $\left(-990 \mu \mathrm{V} / \mathrm{K}\right.$ at $\left.50^{\circ} \mathrm{C}\right)$ of cold-sintered $\mathrm{V}_{2} \mathrm{O}_{5}$ were comparable to conventionally sintered samples and were further increased by the addition of 1-2 vol\% PEDOT:PSS. The current status of cold sintering of $\mathrm{ZrO}_{2}$ has been reviewed by Guo et al.; $\rho_{r} \sim 85 \%$ is achieved by a one-step cold-sintered process at $180{ }^{\circ} \mathrm{C}$ which increased to $\rho_{r} \sim 95 \%$ with comparable Vickers hardness after annealing at $1100^{\circ} \mathrm{C}$, much lower than conventional sintering process $\left(\sim 1400^{\circ} \mathrm{C}\right)$ [79]. The application of cold sintering to solid-state lithium batteries has been reviewed by Liu et al. [46], in which recent progress in different solid electrolytes and electrodes is summarized. Li ion electrolytes and electrodes may be densified but the electrochemical properties of the cold-sintered electrolytes and electrodes required improvement.

\section{The cold sintering process}

Sintering is a process which promotes the coalescence of materials (e.g. powders) into a solid with much higher densities than the initial state. The thermodynamic driving force is lowering of the total surface free energy, i.e. [87]

$$
\Delta \gamma_{A}=\Delta \gamma \times A+\gamma \times \Delta A,
$$

where $\gamma_{\mathrm{A}}$ is total surface free energy, $\gamma$ is surface energy and $A$ is the total specific surface area. During sintering, coarsening of grains contributes to $\Delta \gamma$, whereas the formation of solid-solid interfaces contributes to $\Delta A$. However, $\Delta G$ of a sintering process is only a few tens of $\mathrm{cal} / \mathrm{mol}$, whereas the formation energies of inorganic solid crystals are typically several thousand $\mathrm{cal} / \mathrm{mol}$. A significant energy input is, therefore, required to trigger the sintering process which is usually provided by heating to $\sim 1 / 2$ to $3 / 4$ of a material's melting temperature in ${ }^{\circ} \mathrm{C}$.
Different sintering methods possess different mass transport mechanisms/routes which ultimately lead to different energy (temperature) requirements. Sintering temperature may be reduced by the application of external pressure (e.g. hot pressing) or the addition of a component that forms a liquid at the sintering temperature. Effectively, these two factors act in combination in cold sintering, leading to a dramatic lowering of the sintering temperature for specific materials [42].

Randall et al. [47] utilized $\mathrm{ZnO}$ to study the mechanism(s) of cold sintering, revealing that the gradient of the densification rate varied from 1 to $1 / 3$. They also noticed that the rate of both stages remains almost unchanged with applied pressure, suggesting similar mechanisms are valid over a range of densification conditions. The two different densification rates are attributed to two stages of densification. The first is dominated by particle compaction and rearrangement, whereas the second, with a lower densification rate, relates to a "dissolution-precipitation" mechanism.

\section{Stage 1: particle compaction}

At the beginning of stage 1, particles are separated with a solution/void. Densification at this stage is mainly from the compaction (i.e. external pressure pushes particles closer to each other) and rearrangement of particles, as shown in Fig. 2. The solution will also redistribute at this stage due to the combination of external and capillary pressure [88]. Generally speaking, this stage is similar to dry uniaxial pressing but with three extra factors: transient solution, elevated temperature and higher pressure, which help the process individually and collectively.

The transient solution contributes to the particle rearrangement by (i) acting as a lubricant between particles and assists the rearrangement and sliding process, (ii) exerting capillary pressure to pull the particles closer, and (iii) smoothing the particle surface/shape by dissolving sharp edges and contacts to reduce surface energy, further facilitating particle rearrangement and sliding.

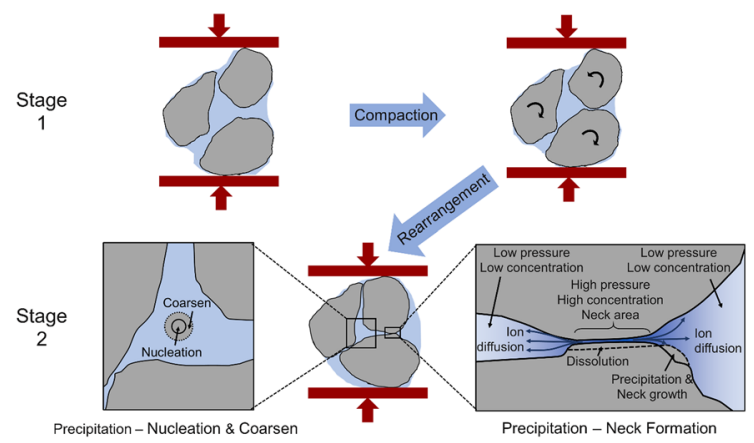

Figure 2: Schematic of cold sintering mechanism at various stages. 
The high pressure is the main driving force to the compaction/rearrangement of particles, but in cold sintering, the solubility of particles also increases according to [89]

$$
\left(\frac{\partial \ln N}{\partial P}\right)_{T}=-\frac{V_{\mathrm{aq}}-V_{\mathrm{cr}}}{R T},
$$

where $N$ is the mole fraction of the component in the solution, $P$ is the pressure, $T$ is temperature, $V_{\mathrm{aq}}$ is the partial molar volume of component in the solution, $V_{\mathrm{cr}}$ is the partial molar volume of component in the dissolving solid, and $R$ is the universal gas constant. The pressure is concentrated at acicular points of contact and sharp edges (GPa can be realized), which promotes preferential dissolution [90], smoothing particles and helping rearrangement. The elevated temperature is not as critical as the transient solution and high pressure at this stage but increases the solubility and accelerates the dissolution. At the end of stage 1 , a relatively rigid skeleton is formed with further particle rearrangement giving only a minor contribution to densification.

\section{Stage 2: dissolution-precipitation and grain coarsening}

Stage 2 relies on filling of gaps/voids between grains. In solid-state sintering, mass transport is achieved via two main mechanisms, evaporation-condensation and diffusion through different routes (e.g. surface, grain boundary). In most cases, the contribution from the former is negligible due to low vapour pressure in air, and mass transport is dominated by solid-state diffusion. However, in cold sintering, the temperature is remarkably lower than that of conventional solid state and solid-state diffusion is unlikely. The solid-gas interface is replaced with a solid-liquid interface and dissolution-precipitation is possible, since the energy required for liquid-phase transport is significantly lower than for solidstate diffusion. Dissolution-precipitation is only viable for compositionally sensitive ceramics, if the material can congruently dissolve. For those systems with limited solubility or exhibit incongruent dissolution, densification may still be achieved but this limits properties.

\section{Congruent dissolution}

Temperature and pressure both influence the solubility of a material. Within a cold sintering system, the distribution of temperature is generally homogeneous but the pressure is concentrated at the contact points. As a result, the solubility is higher which creates a concentration gradient. Solute is then redistributed by diffusion to other locations with lower concentration (i.e. lower pressure), Fig. 2. The concentration gradient induces the Marangoni effect [91] which causes mass transfer along an interface between two fluids due to a gradient of surface tension, caused by local variations in chemical concentration. As the concentration rises, the solution becomes super-saturated to the point where precipitation begins. With the help of external and capillary pressure to keep the particles in close proximity, dissolution-precipitation initially leads to necking, similar to that observed in solid-state sintering, Fig. 2. As the aqueous solution evaporates, coarsening of particles occurs through precipitation on their surface or alternatively new particles nucleate [65], Fig. 2. An amorphous rather than crystalline phase can form if the solute is strongly bonded with solution $[3,56$, 68]. The crystalline phase may, however, be recovered through post-annealing $[57,58]$. We note that the gel/glass phase may be beneficial for the cold sintering process by facilitating plastic flow, thereby filling voids.

\section{Incongruent dissolution and limited dissolution}

Incongruent dissolution means the composition of the solute in solution does not match that of the solid. An inert surface (passive) layer forms from oxide component(s) which is(are) least soluble. In the case of $\mathrm{BaTiO}_{3}, \mathrm{Ba}^{2+}$ ions possess a much higher solubility than $\mathrm{Ti}^{4+}[54]$ and a Ba-depleted layer (i.e. amorphous $\mathrm{TiO}_{2}$ ) forms on the surface of particles. To overcome this issue, a pre-saturated $\mathrm{Ba}(\mathrm{OH})_{2}$ water solution with $\mathrm{TiO}_{2}$ nanoparticle suspension is introduced $[57,58]$. Hydrothermal synthesis takes place at the particle interfaces, densifying the ceramic body, through the formation of a nanocrystalline or amorphous $\mathrm{BaTiO}_{3}$ phase with uniformly distributed $\mathrm{Ba}$ and $\mathrm{Ti}$ ions. The $\rho_{r}$ of the composite is $~ 93 \%$ which can be improved to $96 \%$ by post-annealing at $900{ }^{\circ} \mathrm{C}$ to recrystallize the glass phases [57, 58]. For low solubility compounds such as $\mathrm{Pb}(\mathrm{Zr}, \mathrm{Ti}) \mathrm{O}_{3}$, there is less chance of the formation of a depletion layer and aqueous $\mathrm{Pb}\left(\mathrm{NO}_{3}\right)_{2}$ has been used as the transient solution to achieve $89 \%$ theoretical density [59].

\section{General discussion of the cold sinter process}

Comparing congruent with incongruent dissolution, it is evident that higher density $(\rho)$ is much easier to achieve in the former rather than the latter. In some cases, even the external pressure or elevated temperature is not absolutely necessary if the material is highly soluble $[42,92,93]$ such as lithium molybdate $\left(\mathrm{Li}_{2} \mathrm{MoO}_{4}, \mathrm{LMO}\right)$ and $\mathrm{NaCl}[42,88]$.

Other than the nature of the solvent (e.g. polarity), the solubility may be modified by several factors, including pressure, temperature and particle size (i.e. specific surface area) [94]. The effect of pressure has already been discussed above but temperature follows Le Chatelier's principle [95] which states that solubility increases with increasing temperature for an endothermic reaction (e.g. $\mathrm{NaCl}$ in water), whereas it decreases with the increasing temperature in an exothermic reaction (e.g. $\mathrm{CaCO}_{3}$ in water). 
Smaller particles possess higher solubility due to their higher surface free energy according to

$$
\log \left(* K_{A}\right)=\log \left(* K_{A \rightarrow 0}\right)+\frac{\gamma A_{m}}{3.454 R T},
$$

where ${ }^{\star} K_{A}$ is the solubility constant for the solute particles with the molar surface area $A,{ }^{\star} K_{A \rightarrow 0}$ is the solubility constant for substance with molar surface area tending to zero, $\gamma$ is the surface tension of the solute particle in the solvent, $A_{m}$ is the molar surface area of the solute, $R$ is the universal gas constant, and $T$ is the absolute temperature. However, this effect only becomes significant when the particle size is at the nanoscale.

Finally, we note the solubility can increase through chemical reaction. When water is used as solvent, the solubility of $\mathrm{ZnO}$ is only $0.0004 \%$ at room temperature [96]. Yet when hydrochloric acid is used as solvent, the following reaction takes place:

$$
\mathrm{ZnO}+\mathrm{HCl}=\mathrm{ZnCl}_{2}+\mathrm{H}_{2} \mathrm{O} .
$$

It is therefore reasonable to predict that the outcome of $\mathrm{ZnO}$ cold sintered with water or acid as solution will be different. Funahashi et al. [65] reported that the $\rho_{r}$ of $\mathrm{ZnO}$ after cold sintering is only $65 \%$ when pure water or $0.1 \mathrm{~mol} \mathrm{~L}^{-1}$ acetic acid solution was used, whereas a high $\rho_{r}$ of $>90 \%$ can be achieved with $1 \mathrm{~mol} \mathrm{~L}^{-1}$ acetic acid solution.

Ostwald ripening has also been observed in some cold sintering experiments [97]. However, as Ostwald ripening is strictly a surface effect, it does not involve particle movement, and contributes to particle/grain enlargement but not increasing density.

\section{Microwave dielectric materials and devices by cold sintering}

\section{Monophase materials}

As early as 2014, Kähäri et al. [93] reported the cold sintering of LMO at room temperature with the assistance of deionized water under a pressure of $130 \mathrm{MPa}$, as shown in the backscattered electron (BSE) images, Fig. 3. $\rho_{r}$ of $87-93 \%$ was achieved with $\varepsilon_{r}$ of 4.6-5.2 and $Q \times f$ of 10,200-18,500 after post-annealing. In 2015, the same authors reported that $\rho$ and MW properties of LMO could be improved by an increase of powder particle size, applied pressure and post-processing time [98] but there was no significant effect on $\rho_{r}$ as a function of the amount of deionized water beyond initial wetting.

Guo et al. [42] at 2016 reported a range of monophase coldsintered MW ceramics, Fig. 4, including $\mathrm{NaCl}, \mathrm{LMO}, \mathrm{Na}_{2} \mathrm{Mo}_{2} \mathrm{O}_{7}$ (NMO), $\mathrm{K}_{2} \mathrm{Mo}_{2} \mathrm{O}_{7}, \mathrm{Li}_{2} \mathrm{WO}_{4}, \mathrm{Na}_{2} \mathrm{WO}_{4}, \mathrm{BiVO}_{4}$. With the help of $85 \%$ relative humidity, $\mathrm{NaCl}$ ceramics could be densified to $90 \%$ density at room temperature without applying uniaxial pressure, as shown in Fig. $4 \mathrm{~b}$ ), and was denser than samples sintered at $600^{\circ} \mathrm{C}$ and $700{ }^{\circ} \mathrm{C}\left(\rho_{r}=84 \%\right)$. Significant grain growth (initially $3 \mu \mathrm{m}$ to $20-30 \mu \mathrm{m}$, Fig. $4 \mathrm{~b}$ ) was observed due to the
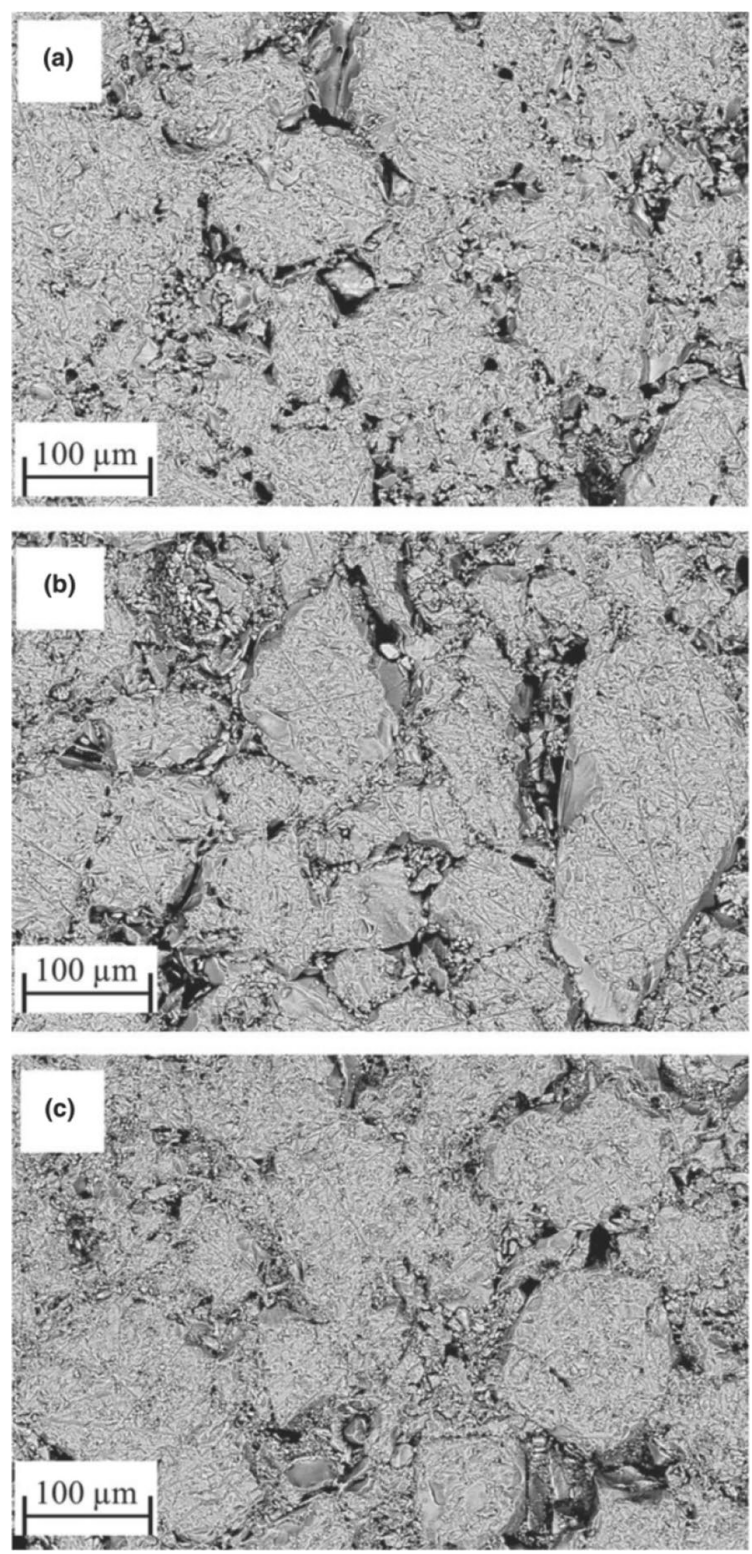

Figure 3: BSE images of cold-sintered LMO ceramic samples, (a) sintered at $540{ }^{\circ} \mathrm{C}$, (b) dried at $120^{\circ} \mathrm{C}$ and (c) dried at room temperature [93].

high aqueous solubility of salt and long holding time. For MW ceramics of low solubility such as LMO (Fig. 4e, $\rho_{r} \sim 95.7 \%$, $\varepsilon_{r} \sim 5.61, Q \times f \sim 30,500$ ), NMO (Fig. 4f, $\rho_{r} \sim 93.7 \%, \varepsilon_{r} \sim 13.4$, $Q \times f \sim 14,900$ ), and $\mathrm{K}_{2} \mathrm{Mo}_{2} \mathrm{O}_{7}$ (Fig. $4 \mathrm{~g}, \rho_{r} \sim 94.1 \%, \varepsilon_{r} \sim 9.8$, $Q \times f \sim 16,000)$, higher temperature $\left(120^{\circ} \mathrm{C}\right)$ and uniaxial pressure $(350 \mathrm{MPa})$ are required.

The following year, Guo et al. [3] proposed that the 'cold sintering offered a new era for ceramic packaging and microwave device development'. To illustrate this point, $(\mathrm{Li}, \mathrm{Bi})_{0.5} \mathrm{MoO}_{4}$ (LBMO) was cold sintered at $120^{\circ} \mathrm{C}$, Fig. S1, with $\rho_{r}$ of $88.5 \%$, $\varepsilon_{r}$ of 33.7, $Q \times f$ of 2300 and $\tau_{f}$ of $+184 \mathrm{ppm} /{ }^{\circ} \mathrm{C}$. The grain size of cold-sintered LBMO was limited to the initial particle size of 

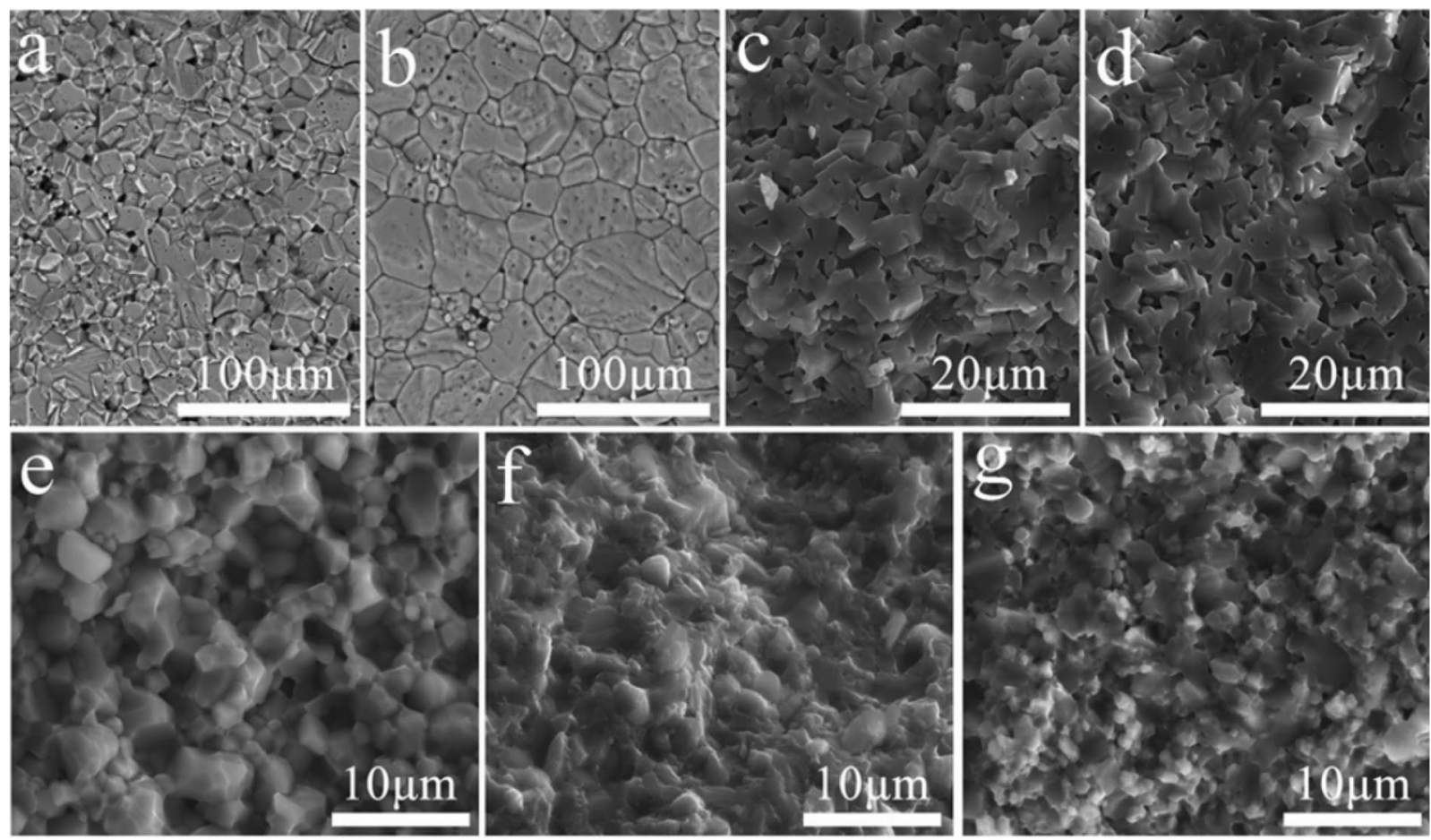

Figure 4: SEM images of $\mathrm{NaCl}$ sintered at (a) room temperature and $75 \%$ relative humidity for $24 \mathrm{~h}$, (b) room temperature and $85 \%$ relative humidity for $10 \mathrm{~h}$, (c) $600{ }^{\circ} \mathrm{C}$ for $50 \mathrm{~min}$ and (d) $700^{\circ} \mathrm{C}$ for $10 \mathrm{~min}$. Cross-section SEM images of (e) LMO, (f) NMO and (g) $\mathrm{K}_{2} \mathrm{Mo}_{2} \mathrm{O}_{7}$ ceramics cold sintered at $120^{\circ} \mathrm{C}$ and $350 \mathrm{MPa}$ for $15 \mathrm{~min}$ [42].

ceramic powders, since most systems were coarse-grained and do not achieve $>92 \%$ density and grain growth is suppressed.

Hong et al. [92, 99] systematically studied the effect of applied pressure and water on cold sintering of $\mathrm{NaCl}$ ceramics at room temperature. As applied uniaxial pressure increased, $\rho_{r}$ of dry $\mathrm{NaCl}$ water increased from $80 \%$ (50 MPa) to $99.3 \%$ (300 MPa), which is due to the plastic deformation [92]. They found that the addition of $4 \%$ water promoted the dissolution-precipitation process, giving a homogenous microstructure, leading to $\rho_{r} \sim 99.3 \%$ and optimal MW properties, $\varepsilon_{r} \sim 5.55, Q \times f \sim 49,600 \mathrm{GHz}$ and $\tau_{f} \sim-173 \mathrm{ppm} /{ }^{\circ} \mathrm{C}$ at $300 \mathrm{MPa}$, as plotted in Fig. S2. The same authors [99] also found that $\rho_{r}$ and $\varepsilon_{r}$ decreased from 99.3 to $93.4 \%$ and 5.88 to 5.44 , respectively, with excess water from 0 to $10 \%$, which was attributed to the volume increase caused by the water evaporation. The highest $Q \times f(49,600 \mathrm{GHz})$ was obtained with $4 \%$ water, due to the homogenous microstructure.

Recently, Wang et al. reported several cold-sintered MW ceramics with $4.7<\varepsilon_{r}<30$, such as $\mathrm{Na}_{0.5} \mathrm{Bi}_{0.5} \mathrm{MoO}_{4}$ (NBMO, $\rho_{r} \sim 84.9 \%, \varepsilon_{r} \sim 20.7, Q \times f \sim 1500, \tau_{f} \sim+46 \mathrm{ppm} /{ }^{\circ} \mathrm{C}$ ) [100], $\left(\mathrm{Bi}_{0.95} \mathrm{Li}_{0.05}\right)\left(\mathrm{V}_{0.9} \mathrm{Mo}_{0.1}\right) \mathrm{O}_{4}$ (BLVMO, $\rho_{r} \sim 73 \%, \varepsilon_{r} \sim 30$, $\left.Q \times f \sim 1300, \tau_{f} \sim+61 \mathrm{ppm} /{ }^{\circ} \mathrm{C}\right)[101], \mathrm{KCl}\left(\rho_{r} \sim 98 \%, \varepsilon_{r} \sim 4.74\right.$, $\left.Q \times f \sim 7738, \tau_{f} \sim-149 \mathrm{ppm} /{ }^{\circ} \mathrm{C}\right)[101], \mathrm{K}_{2} \mathrm{MoO}_{4}(\mathrm{KMO}$, $\left.\rho_{r} \sim 100 \%, \varepsilon_{r} \sim 6.37, Q \times f \sim 26,500, \tau_{f} \sim-70 \mathrm{ppm} /{ }^{\circ} \mathrm{C}\right)[101]$, and $\mathrm{AgNaMoO}_{4}\left(\mathrm{ANMO}, \rho_{r} \sim 90.8 \%, \varepsilon_{r} \sim 9.3, Q \times f \sim 7078\right.$, $\left.\tau_{f} \sim-120 \mathrm{ppm} /{ }^{\circ} \mathrm{C}\right)[101]$, as listed in Table S1. The majority of the above are based on molybdates but recently, lower cost $\mathrm{LiMgPO}_{4}$ (LMP, $\rho_{r} \sim 93 \%, \varepsilon_{r} \sim 6.5, Q \times f \sim 16,000$ ) MW ceramics were also successfully cold sintered [102], Fig. 5. In this work, with the increase of cold sintering temperature and time, $\rho_{r}$ and $\varepsilon_{r}$ were enhanced (Fig. $5 \mathrm{a}, \mathrm{b}$ ) and slightly higher than conventionally sintered samples ( $\rho_{r} \sim 92 \%$ and $\left.\varepsilon_{r} \sim 6.4\right)$. In addition, no impurity or secondary phase was observed during the cold sintering process, as shown in Fig. 5d, e.

\section{Composite materials}

Despite promising values of $Q \times f$ and $\varepsilon_{r}$ for MW applications, no monophasic ceramics have to date been shown to be temperature stable $\left(\tau_{f} \sim 0\right)$. Kähäri et al. [98] attempted to tune $\tau_{f}$ and reported cold-sintered LMO ceramics with the addition of 10 vol\% $\mathrm{TiO}_{2}$ and $\mathrm{BaTiO}_{3}$ at $120^{\circ} \mathrm{C}$, respectively, as shown in Fig. 6, which led to the increase of $\varepsilon_{r}$ and loss tangent (Table S2). The effect of different amounts of $\mathrm{TiO}_{2}$ on the microstructure and $\mathrm{MW}$ dielectric properties of LMO was also investigated in a related study [103]. $\varepsilon_{r}$ increased from $5.1\left(0 \mathrm{vol} \% \mathrm{TiO}_{2}\right)$ to 10.1 (30 vol\% $\left.\mathrm{TiO}_{2}\right)$, as listed in Table $\mathrm{S} 3$ [98], but $\tau_{f}\left(+20 \mathrm{ppm} /{ }^{\circ} \mathrm{C}\right)$ remained stubbornly, high even with 20 vol\% $\mathrm{TiO}_{2}$ (Table S3) [103]. 

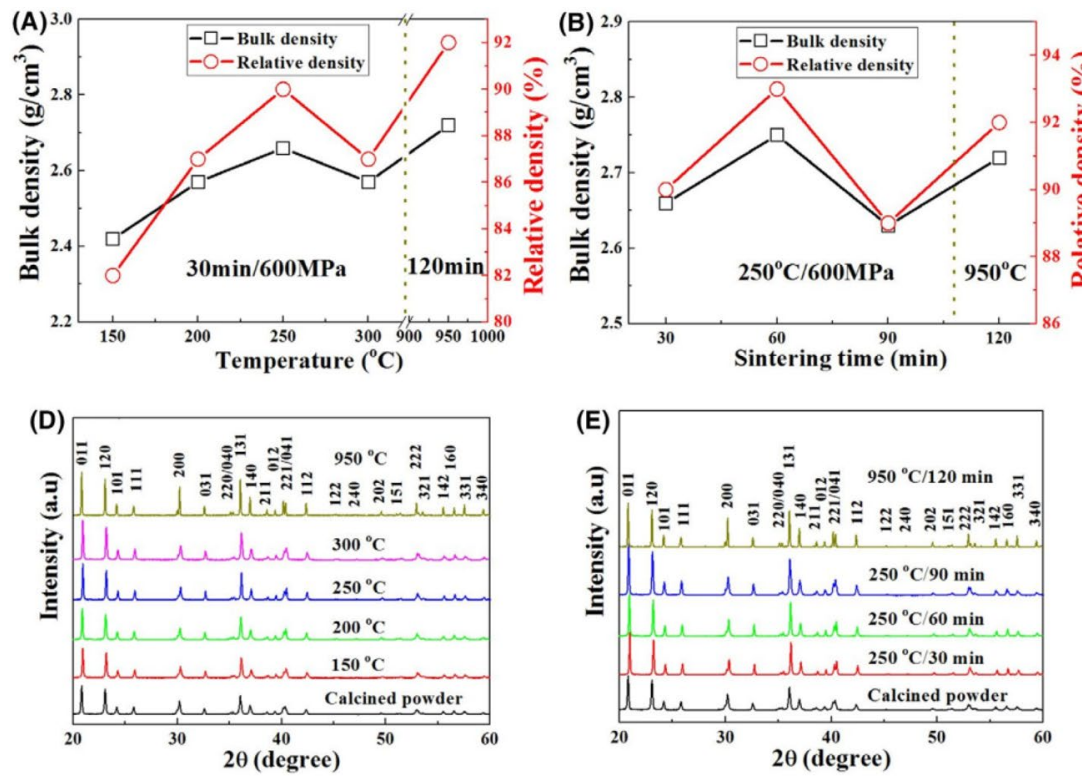
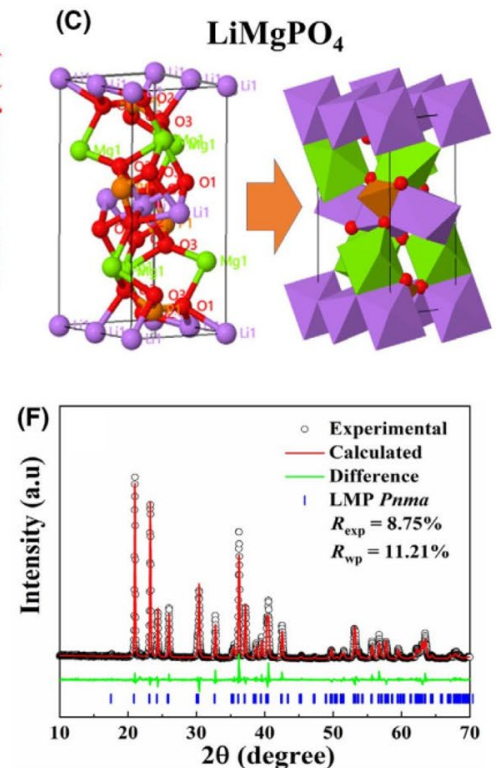

Figure 5: $\rho$ and $\rho_{r}$ of LMP ceramics as a function of (a) sintering temperature and (b) sintering time. (c) The schematic crystal structure of LMP. XRD patterns of LMP ceramics cold sintered at different (d) sintering temperatures and (e) sintering times. (f) Rietveld refinement of cold-sintered LMP ceramics [102].
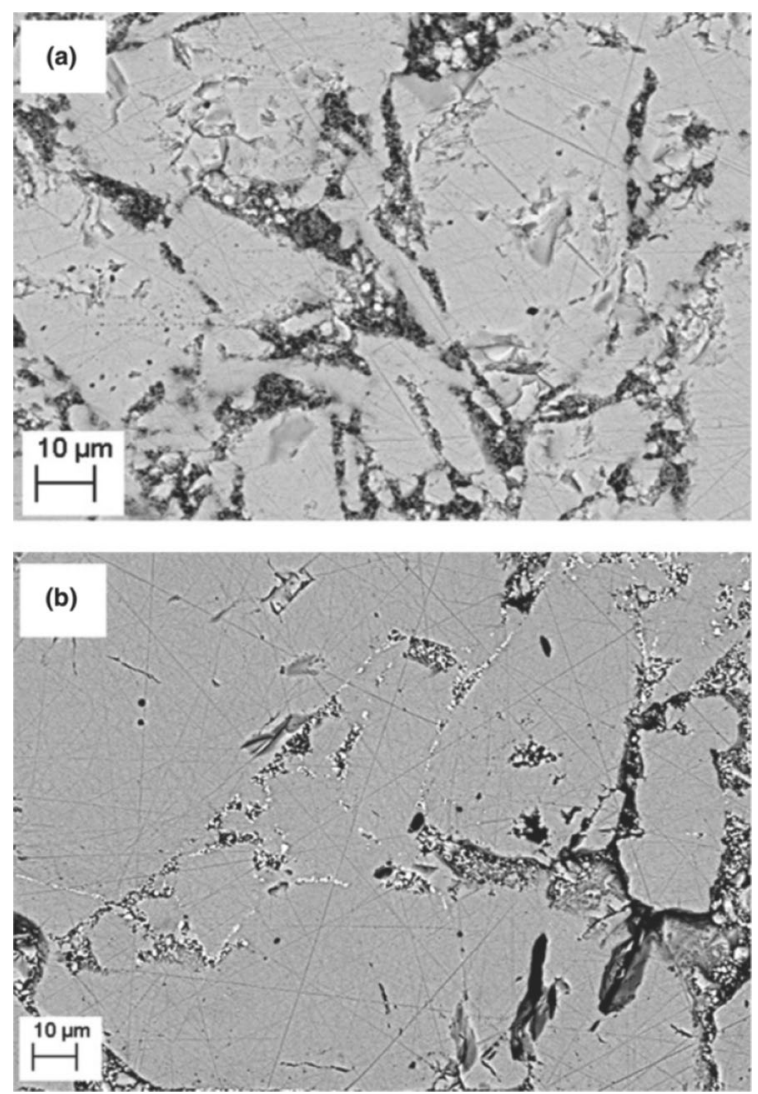

Figure 6: $B S E$ images of $\mathrm{LMO}$ ceramic composites with an addition of (a) 10 vol\% of $\mathrm{TiO}_{2}$ and (b) 10 vol\% of $\mathrm{BaTiO}_{3}$ [98].
In 2016, Guo et al. [43] proposed that cold sintering bridged the processing temperature gap of ceramic and polymer materials, schematically shown in Fig. 7a and reported several series of ceramic-polymer composites (LMO- $\left(-\mathrm{C}_{2} \mathrm{~F}_{4}-\right)_{n}$ (PTFE), electrolyte $\mathrm{Li}_{1.5} \mathrm{Al}_{0.5} \mathrm{Ge}_{1.5}\left(\mathrm{PO}_{4}\right)_{3}-\left(-\mathrm{CH}_{2} \mathrm{CF}_{2}-\right)_{x}\left[-\mathrm{CF}_{2} \mathrm{CF}\left(\mathrm{CF}_{3}\right)-\right]_{y}$ (PVDF-HFP), semiconductor $\mathrm{V}_{2} \mathrm{O}_{5}$-PEDOT:PSS). High density $\left(\rho_{r}>93 \%\right)$ and homogenous microstructure were obtained for LMO-xPTFE $(0 \leq x \leq 70 \mathrm{vol} \%)$, as shown in the BSE images, Fig. 7b, c. Furthermore, by integrating different electrical and mechanical features of both ceramic and polymer, novel composites with integrated properties could be designed and achieved, Fig. 8. As PTFE concentration increased, $\varepsilon_{r}$ of LMOxPTFE decreased from 5.8 to $2.9, \tau_{f}$ shifted from -170 to $-7.2 \mathrm{ppm} /{ }^{\circ} \mathrm{C}$, elastic modulus and shear modulus decreased, while no obvious deterioration was observed in $Q \times f$, Fig. $8 \mathrm{~b}-\mathrm{f}$.

Inspired by Guo et al., many novel MW dielectric ceramic-ceramic/polymer composites were further developed, including LBMO-PTFE [3], $\mathrm{Al}_{2} \mathrm{SiO}_{5}-\mathrm{NaCl}$ [104], LMO-MnZn [105], NBMO-LMO [100], LMO-BaFe ${ }_{12} \mathrm{O}_{19}$

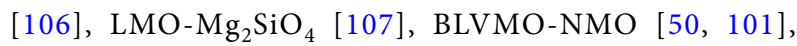
$\mathrm{CaTiO}_{3}(\mathrm{CTO})-\mathrm{KMO}$ [51], $\mathrm{Bi}_{2} \mathrm{Mo}_{2} \mathrm{O}_{9}(\mathrm{BMO})-\mathrm{KMO}$ [52], garnet-LMO/ $\mathrm{NaCl}$ [108], and LMP-CTO-KMO [102]. Most pertinently however, Wang, Reaney and co-workers developed several MW ceramic composites with near-zero $\tau_{f}$ which exhibited a wide range of $\varepsilon_{r}$, such as $8 \mathrm{wt} \% \mathrm{CTO}-92 \mathrm{wt} \% \mathrm{KMO}$ (Fig. S3, $\varepsilon_{r} \sim 8.5$ ) [51], $50 \mathrm{wt} \% \mathrm{LMP}-10 \mathrm{wt} \% \mathrm{CTO}-40 \mathrm{wt} \% \mathrm{KMO}$ $\left(\varepsilon_{r} \sim 9.1\right) \quad[102], 65$ wt $\% \mathrm{CaSnSiO}_{5}-35$ wt $\% \mathrm{KMO}$ 
(a)

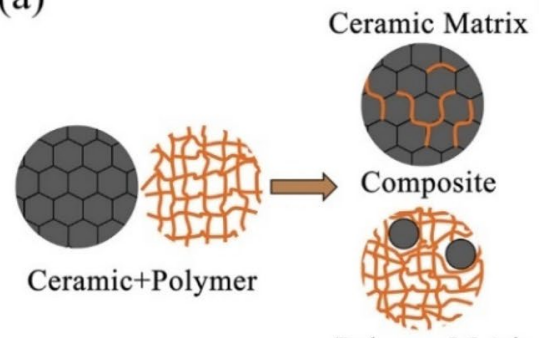

Polymer Matrix (b)

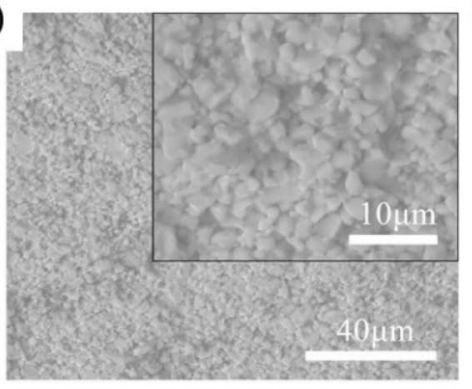

(c)

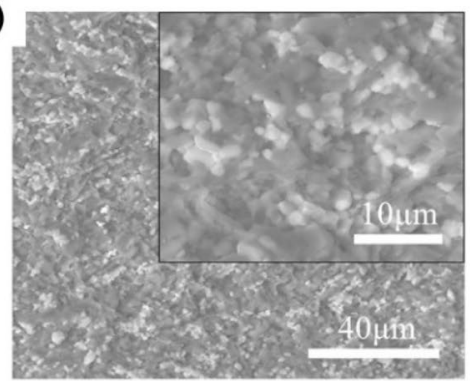

Figure 7: (a) Schematic of cold-co-sintered ceramic-polymer composites with different amounts of polymer. BSE images of (b) 0.9LMO-0.1PTFE and (c) 0.4LMO-0.6PTFE composites cold sintered at $120^{\circ} \mathrm{C}$ and $350 \mathrm{MPa}$ for $20 \mathrm{~min}$ [43].

a

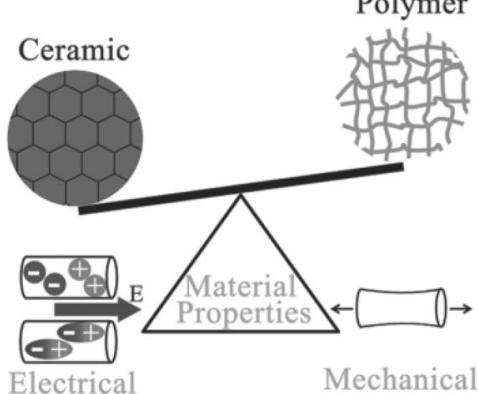

d

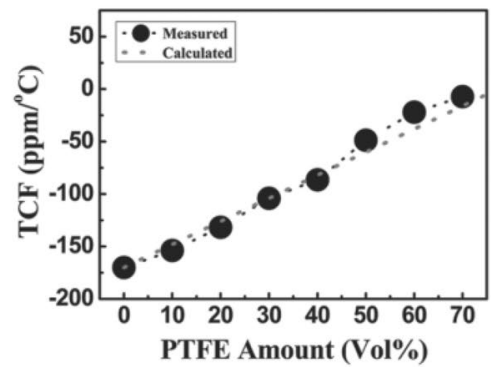

b

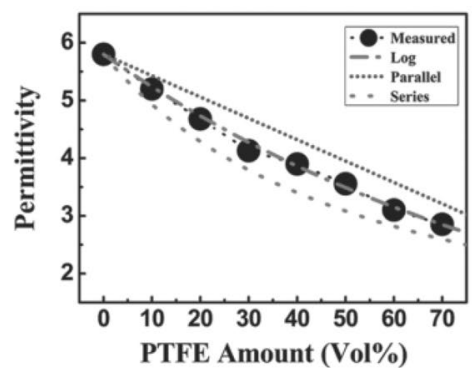

e

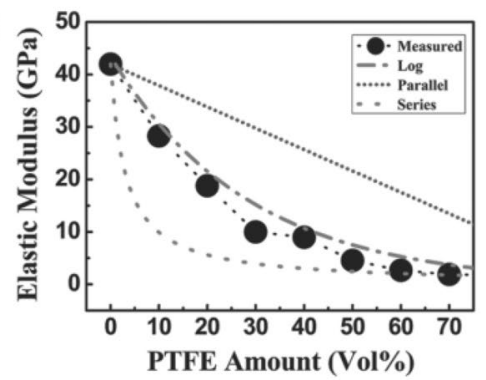

c

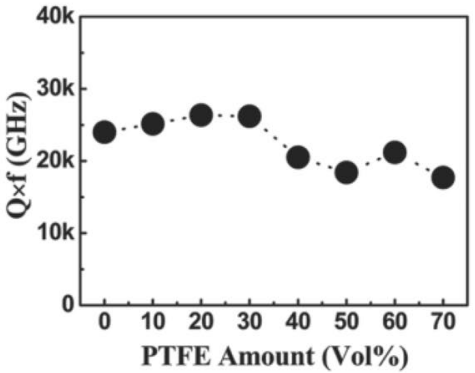

$f$

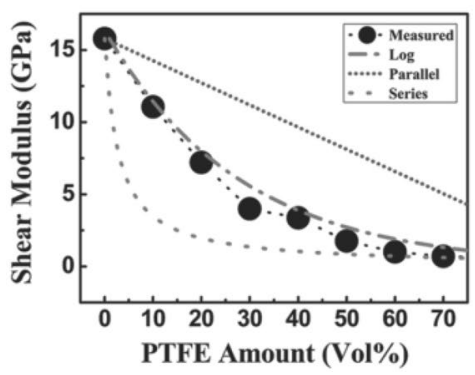

Figure 8: (a) Schematic of integrated material properties by balancing ceramic/polymer ratio. Electrical and mechanical properties of LMO-PTFE composites as a function of PTFE volume fraction: (b) $\varepsilon_{r^{\prime}}$ (c) $\left(Q \times f\right.$, (d) TCF $\left(\tau_{f}\right)$, (e) elastic modulus and (f) shear modulus [43].

$\left(\varepsilon_{r} \sim 9.2\right)$ [109], $80 \mathrm{wt} \% \mathrm{NBMO}-20 \mathrm{wt} \% \mathrm{LMO}\left(\varepsilon_{r} \sim 17.4\right)$ [100], 90 wt $\% \mathrm{BMO}-10 \mathrm{wt} \% \mathrm{KMO}\left(\varepsilon_{r} \sim 31\right)$ [52], and $80 \mathrm{wt} \% \mathrm{BLVMO}-20 \mathrm{wt} \% \mathrm{NMO}\left(\varepsilon_{r} \sim 40\right)$ [50, 101]. All compositions could be co-fired with polymers and Ag/base-metal electrode without interaction (Fig. S3k,1) [51, 109] and had the potential to be used in antennas, resonators, filters and capacitors.

The fabrication of ceramic-ceramic layered composites is difficult by conventional sintering technology, due to interfacial reaction, delamination and wrapping, caused by inequivalent densification rates and differential thermal expansion on cooling. These issues are completely resolved by cold sintering either due to the ultralow sintering temperatures or the absence of lateral shrinkage. Wang et al. demonstrated using NBMOxLMO (Fig. 9A), a three-layered macroscopic ceramic-ceramic graded dielectric composite for the fabrication of MW dielectric GRaded INdexed (GRIN) lenses, Fig. 9B [100]. The graded composite had a high density with no delamination or wrapping.

To our knowledge, all MW ceramics and composites fabricated to date by cold sintering are summarized in Table 1 which illustrates the range of $\varepsilon_{r}, \tau_{f}$ and $Q \times f$ values which can be achieved and indicates their great promise for fabrication of RF devices.

\section{RF devices}

To demonstrate the potential of cold sintering for RF applications, different devices have been designed and fabricated. In 2016, Baker et al. printed LMO monolithic capacitors on PET/ $\mathrm{Ni}$ foil substrates with $\mathrm{Ag}$ internal electrodes [53], as shown in 
(A)

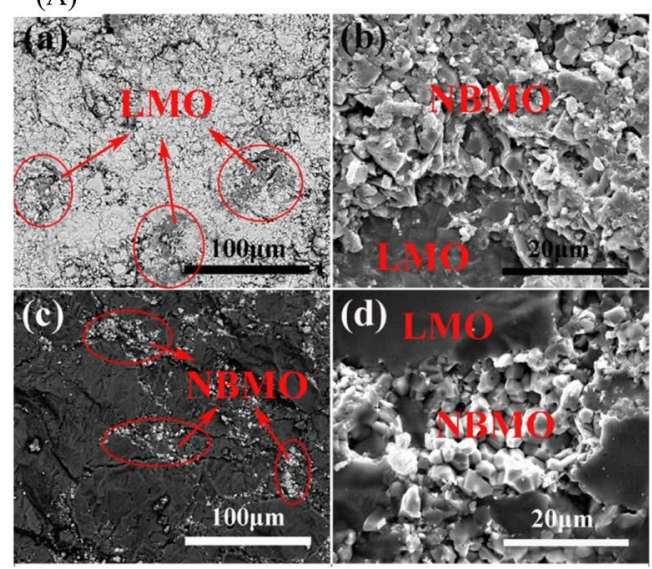

(B) (a)

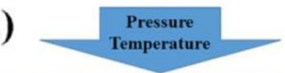

\section{$\mathrm{NI}$}
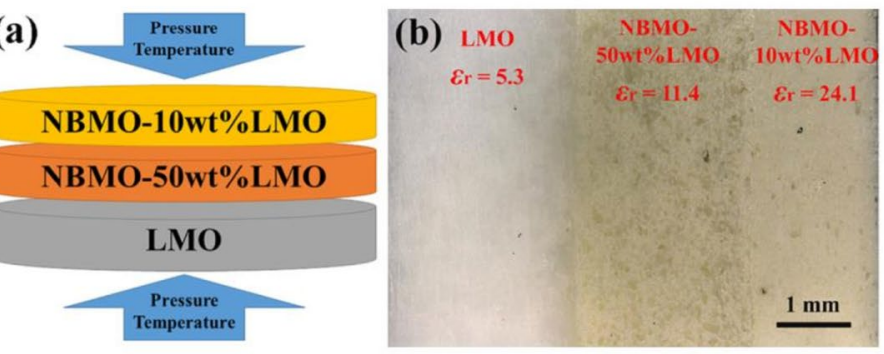

Figure 9: (A) BSE and SEM images of cold-sintered (a, b) 90 wt $\%$ NBMO-10 wt\%LMO and (c, d) 20 wt\%NBMO-80 wt $\%$ LMO composite samples; (B) (a) schematic illustration and (b) optical picture of the NBMO-LMO three-layered composite ceramics [100].

TABLE 1: Comparison of $\rho_{r}$ and $\mathrm{MV}$ properties of cold-sintered MV materials (PTFE $=$ Polytetrafluoroethylene, $\mathrm{LMO}=\mathrm{Li}_{2} \mathrm{MoO}_{4}$ $\mathrm{KMO}=\mathrm{K}_{2} \mathrm{MoO}_{4}, \mathrm{NMO}=\mathrm{Na}_{2} \mathrm{Mo}_{2} \mathrm{O}_{7}$ $\mathrm{NBMO}=\mathrm{Na}_{0.5} \mathrm{Bi}_{0.5} \mathrm{MoO}_{4}, \mathrm{BLVMO}=$

$\left(\mathrm{Bi}_{0.95} \mathrm{Li}_{0.05}\right)\left(\mathrm{V}_{0.9} \mathrm{Mo}_{0.1}\right) \mathrm{O}_{4}, \mathrm{LMP}=$ $\mathrm{LiMgPO}_{4}, \mathrm{CTO}=\mathrm{CaTiO}_{3}, \mathrm{BMO}=$ $\mathrm{Bi}_{2} \mathrm{Mo}_{2} \mathrm{O}_{9}$, Garnet $=\left(\mathrm{Fe}_{1.72} \mathrm{Mg}_{0.8} \mathrm{Mn}_{0.0}\right.$ $\left.\left.\mathrm{Ca}_{0.02}\right)\left(\mathrm{Fe}_{0.04} \mathrm{Al}_{2.36}\right) \mathrm{Si}_{2.93} \mathrm{O}_{12}\right)$.

\begin{tabular}{|c|c|c|c|c|c|}
\hline Compound & $\rho_{r}(\%)$ & $\varepsilon_{r}$ & $Q \times f(G H z)$ & $\tau_{f}\left(\mathrm{ppm} /{ }^{\circ} \mathrm{C}\right)$ & References \\
\hline LMO-70vol\%PTFE & - & 2.9 & $\sim 17,000$ & -7.2 & [43] \\
\hline $\mathrm{HBO}_{2}-\mathrm{II}$ & 94.7 & 4.21 & 47,500 & -70 & [110] \\
\hline $\mathrm{Al}_{2} \mathrm{SiO}_{5}-50 \mathrm{wt} \% \mathrm{NaCl}$ & - & 4.52 & 22,350 & -24 & [104] \\
\hline $\mathrm{KCl}$ & 98 & 4.74 & 7738 & -149 & [101] \\
\hline LMO-20wt $\% \mathrm{Mg}_{2} \mathrm{SiO}_{4}$ & 90 & 5.05 & 16,030 & - & [107] \\
\hline LMO & 95.5 & $5.1-5.61$ & $10,200-30,500$ & -170 & {$[42,93,98,100,101]$} \\
\hline $\mathrm{NaCl}$ & $97-99$ & $5.22-5.55$ & $12,000-49,600$ & -100 & {$[42,92,99,101,104]$} \\
\hline LMO-15 wt\%BaFe ${ }_{12} \mathrm{O}_{19}$ & 94.1 & 5.8 & 17,430 & - & {$[106]$} \\
\hline KMO & 100 & 6.37 & 26,500 & -70 & [101] \\
\hline LiF & 78 & 6.4 & 4487 & - & [111] \\
\hline LMP & 93 & 6.5 & 16,000 & - & [102] \\
\hline LMO-10 vol\% $\% \mathrm{TiO}_{2}$ & - & 6.7 & $\sim 6714$ & - & [98] \\
\hline Garnet-50 wt $\% \mathrm{NaCl}$ & 95 & 6.8 & 5400 & -113 & [108] \\
\hline Garnet-50 wt\%LMO & 88 & 7.6 & 2300 & -124 & [108] \\
\hline LMO-10 vol\%BaTiO ${ }_{3}$ & - & 8.2 & $\sim 354$ & - & [98] \\
\hline KMO-8 wt\%СTO & 100 & 8.5 & 11,000 & -4 & [51] \\
\hline LMO-20 vol\% $\% \mathrm{TiO}_{2}$ & 88 & 8.7 & $\sim 4000$ & +20 & [103] \\
\hline LMP-10 wt\%CTO-40 wt\%KMO & 97 & 9.1 & 8500 & +6 & [102] \\
\hline CaSnSiO5-35 wt\%KMO & 98.6 & 9.2 & 6249 & -0.5 & [109] \\
\hline $\mathrm{AgNaMoO}_{4}$ & 90.8 & 9.3 & 7078 & -120 & [101] \\
\hline $\mathrm{K}_{2} \mathrm{Mo}_{2} \mathrm{O}_{7}$ & $94.1-96$ & $9.35-9.8$ & $12,000-16,000$ & -63 & [42] \\
\hline $\mathrm{MoO}_{3}$ & 83.7 & 9.91 & 11,800 & -39 & [81] \\
\hline NMO & 93.7-95 & $12.7-13.4$ & $12,000-14,900$ & -99 & [42] \\
\hline NBMO-20 wt\%LMO & 93.6 & 17.4 & 7470 & -4.7 & [100] \\
\hline NBMO & 84.9 & 20.7 & 1500 & +46 & [100] \\
\hline LMO-30 vol\%MnZn & $84-87$ & 21.7 & - & - & [105] \\
\hline BMO-50wt\%KMO & 100 & 22 & 1300 & -55 & [52] \\
\hline NBMO-10 wt\%LMO & 92.6 & 24.1 & 2240 & +15 & [100] \\
\hline BLVMO & 73 & 30 & 1300 & +61 & [101] \\
\hline BMO-10 wt\%KMO & 100 & 31 & 3000 & -1 & [52] \\
\hline $\mathrm{Bi}_{2} \mathrm{O}_{3}$ & 98.31 & 32.2 & 16,425 & - & [82] \\
\hline$(\mathrm{LiBi})_{0.5} \mathrm{MoO}_{4}$ & 88 & $33.7-37$ & $1700-2300$ & +180 & [3] \\
\hline BLVMO-20 wt\%NMO & 96 & 40 & 4000 & +4 & {$[50,101]$} \\
\hline СТО-20 wt\%KMO & 89 & 46.6 & 1000 & +317 & {$[51]$} \\
\hline BLVMO-10 wt\%NMO & 95 & 48 & 3959 & +20 & [101] \\
\hline
\end{tabular}



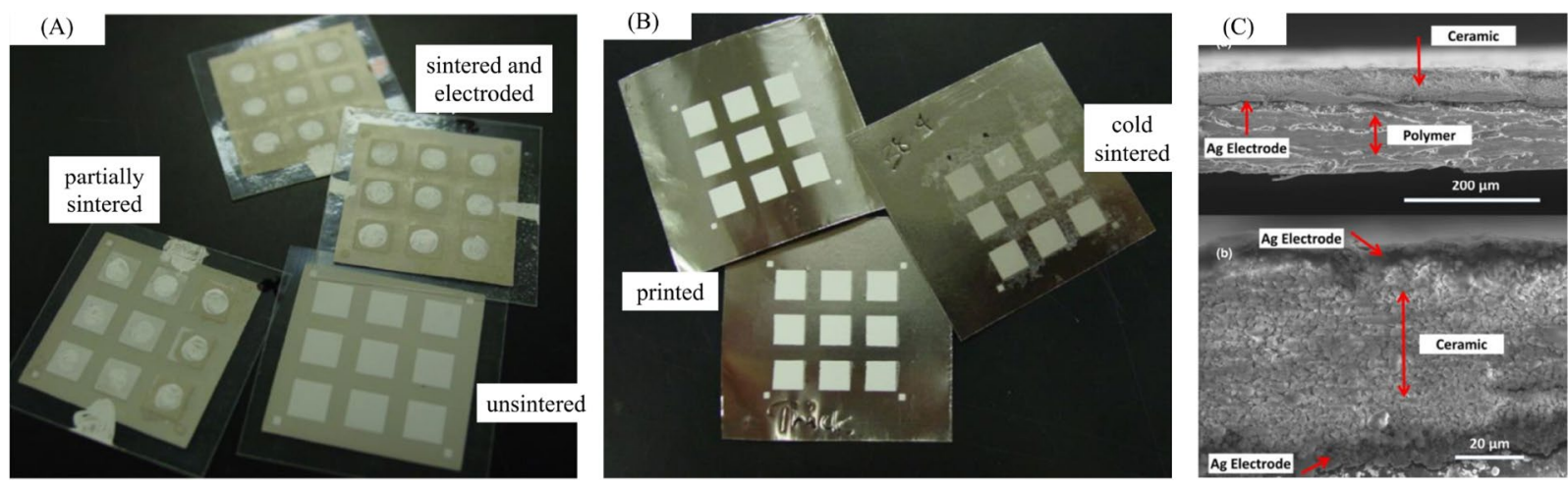

Figure 10: Photograph of (A) printed LMO capacitors on PET films and (B) printed LMO capacitors on Ni foils; (c) cross-sectional SEM images of a coldsintered single-layered LMO capacitor [53].

Fig. 10, thereby demonstrating a facile and flexible method for the production of single and multilayer capacitors using cold sintering, Fig. S4 [3].

Simultaneously, the first microstrip patch antenna was designed and fabricated using a cold-sintered LMO disk as a substrate, Fig. 11 [112]. Lateral dimensions were controlled by the mould, simplifying the design/modelling of the antenna performance. However, due to high relative humidity (80\%) and water absorption, a lower $f_{0}$ and a reduced antenna efficiency were observed compared to the simulated results, which was subsequently resolved using a silicone conformal coating.

Wang et al. also designed and simulated a novel dielectric GRIN lens based on cold-sintered NBMO-xLMO [100] and BLVMO-xNMO [101] ceramic systems (Fig. S5) which exhibited good aperture efficiencies of $78 \%$ and $70 \%$, respectively. Furthermore, BLVMO-NMO-based multilayer ceramic capacitors (MLCCs) were successfully cold sintered at $150{ }^{\circ} \mathrm{C}$ with $\mathrm{Ag}$ internal electrodes without evidence of interfacial reaction, delamination and wrapping (Fig. 12); [50] the dielectric properties of which $\left(\varepsilon_{\mathrm{r}}=39, \mathrm{TCC} \approx \pm 0.01 \%, \tan \delta=0.01\right.$ at $\left.1 \mathrm{MHz}\right)$ corresponded to a C0G designation $\left( \pm 30 \mathrm{ppm} /{ }^{\circ} \mathrm{C}\right)$ in the Electronic Industry Alliance codes.

Following on from Kohari et al. Wang et al. [51] utilized a temperature stable cold-sintered composition, CTO-KMO, to design and fabricated a microstrip patch antenna $(40.0 \mathrm{~mm} \times 40.0 \mathrm{~mm} \times 1.4 \mathrm{~mm})$, with copper tape $(27.5 \mathrm{~mm} \times 23.0 \mathrm{~mm} \times 0.05 \mathrm{~mm})$ as the radiation element and ground plane, as shown in the inset of Fig. 13a. The microstrip patch antenna operated at a centre operating frequency of $\sim 2.5 \mathrm{GHz}$ (Fig. 13a) and the realized gain was $2.73 \mathrm{dBi}$ at $2.5 \mathrm{GHz}$, leading to a radiation efficiency of $62 \%$ [51].

A $5 \mathrm{G}$ prototype microstrip patch antenna was further fabricated by $\mathrm{Li}$ et al. [109] using cold-sintered $\mathrm{CaSnSiO}_{5}-\mathrm{KMO}$ composite ceramics, as shown in the inset of Fig. S6a, which exhibited a centre operating frequency of $5.2 \mathrm{GHz}$ with good impedance match and a $144 \mathrm{MHz}$ bandwidth (-10 dB) (Fig.
S6a). A high total efficiency of $88.4 \%$ was obtained in this antenna at the frequency of $5.2 \mathrm{GHz}$ with an antenna gain of $5.7 \mathrm{dBi}$ (Fig. S6c), again suggesting $\mathrm{CaSnSiO}_{5}-\mathrm{KMO}$ compositions are suitable for antenna applications.

Most importantly from a manufacturing perspective, Wang et al. [52] have demonstrated that cold-sintered, temperature stable $0.9 \mathrm{BMO}-0.1 \mathrm{KMO}\left(30 \times 30 \times 7 \mathrm{~mm}, \varepsilon_{r} \sim 31\right)$ could be directly pressed onto PCBs $\left(\mathrm{T}_{\mathrm{M}}<200{ }^{\circ} \mathrm{C}\right)$ with a satellite navigation antenna subsequently fabricated using the standard Cu metallization as the ground plane, as shown in Fig. 14A [52]. No chemical reaction/delamination was observed at the interface between ceramic and $\mathrm{Cu}$ layers, as shown in the SEM images and EDS elemental line-scans in Fig. 14B. An S11 of $-10 \mathrm{~dB}$ and a bandwidth of $59 \mathrm{MHz}$ was measured in the antenna with an axial ratio $<3 \mathrm{~dB}$ (Fig. 14C), which covered the desired frequency bands $1561 \mathrm{MHz}$ for BeiDou and $1575 \mathrm{MHz}$ for GPS/Galileo with high efficiencies of $87-88 \%$, as shown in Fig. 14D. This latter contribution demonstrates the potential of cold sintering for the fabrication of low-cost integrated ceramic-polymer substrate technology, opening up new design space for a plethora of directly integrated devices ranging from antennas to dielectric resonator arrays. In addition to the reduction in manufacturing costs, the much lower temperature with cold sintering enables precise control of lateral dimensions of the ceramic body, which is a great asset in manufacturing since $f_{0}$ is determined based on the mould dimensions (no lateral shrinkage) and the powder charge without the need for post-fabrication tuning, a weakness in conventional processing.

\section{Summary and perspectives}

In this contribution, the underpinning principles of MW ceramic technology and cold sintering have been reviewed. MW ceramics and RF devices (substrates, resonators, filters, etc.) are widely used in wireless and satellite communication technology, recently accelerated by the deployment of $5 \mathrm{G}$ and ultimately $\mathrm{mm}$-wave networks. They are manufactured typically 
(A)
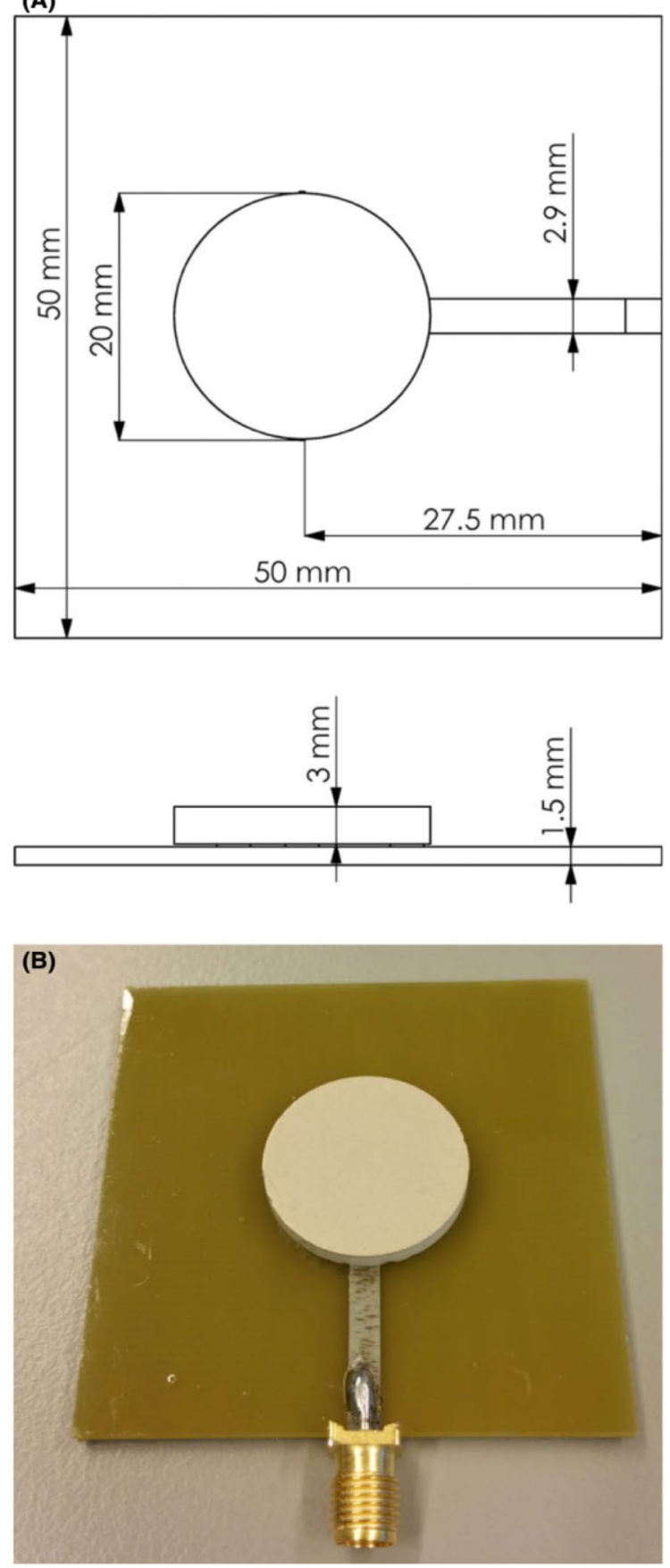

Figure 11: (A) Layout and cross section of the designed antenna and (B) image of a fabricated circular LMO patch antenna [112].

at high temperatures and are expensive due to the large amount of energy required for densification in addition to the high raw materials costs. Cold sintering, particularly for congruent dissolving ceramics and composites, offers, through its unique "dissolution-precipitation" process, a feasible and sustainable technology to realize ultralow-temperature and low-carbon manufacturing of MW devices. Temperature stable cold-sintered compositions are now available with $2.9<\varepsilon_{r}<48$ and $Q \times f$ suitable for a wide range of applications. Furthermore, the unique compatibility that cold sintering offers with polymers and metals creates a hitherto, unexplored design space for component fabrication and manufacturing, such as directly integrated ceramics on metallized PCBs and new functionality through graded structures. However, several critical issues need to be addressed in future:

(1) Although the cold sintering process has been investigated and discussed by Randall et al. [47], its mechanism(s) still require(s) further clarification. At the moment, the prevailing view is that there are strong similarities with liquid-phase sintering but we acknowledge that the exact processes that occur inside the die at temperature and pressure still remain to be elucidated.

(2) Most cold-sintered MW ceramics and composites are molybdates or molybdate based. The high cost of Mo means that any economic benefit from reduction of energy in manufacturing may be lost in the high cost of raw material. Industry would like to see drop-in replacements for conventional ceramics based on e.g. $\mathrm{Al}_{2} \mathrm{O}_{3}, \mathrm{TiO}_{2}, \mathrm{CaTiO}_{3}$ and $\mathrm{SrTiO}_{3}$. However, these materials are poorly soluble and require complex cold-sintered approaches that do not readily maintain high $Q \times f$ values. Cold-sintered compositions based on phosphates look to be a potential way to decrease cost while retaining usable properties, with initial success recently demonstrated by Wang et al. [102].

(3) Although many MW ceramics and composites can be densified by cold sintering, most of their $Q \times f$ values are quite low compared to samples sintered conventionally. $Q \times f$ for resonators is required to be $>40,000 \mathrm{GHz}$ for most applications but to date this seems beyond the reach of cold-sintered, temperature stable compositions. Randall et al. [47] attribute this phenomenon to the complex microstructure of grain boundary (amorphous phase, interfacial films, etc.) and limited grain growth (small grain size). It is critical, therefore, to modify the process of cold sintering to eliminate interfacial amorphous phase and promote grain growth so that $Q \times f$ may be optimized. There are nascent related technologies based on hybrid techniques such cold/flash sintering or MW-assisted cold sintering that could, if successfully developed, not only expand the range of cold-sintered ceramics but also improve the interparticle interface and thus $Q \times f$.

(4) Sensitivity to atmospheric moisture due to the partially soluble nature of cold-sintered ceramics may also pose issues for long-term usage. In addition, mechanical properties (and thus handling characteristics) have been reported to be significantly worse than their con- 

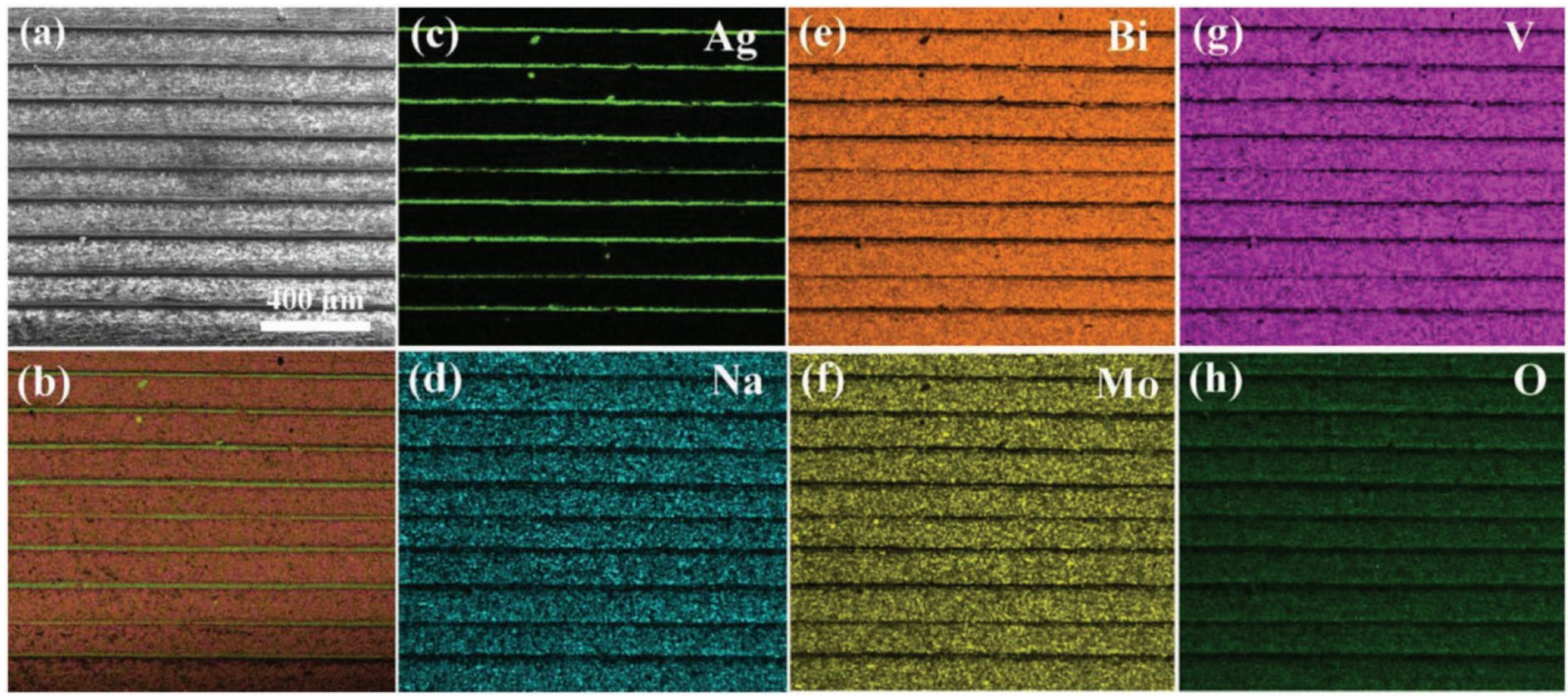

Figure 12: (a) SEM image for the cross section of BLVMO-NMO MLCCs; EDS elemental mapping: (b) elemental layered image, (c) Ag, (d) $\mathrm{Na}$, (e) $\mathrm{Bi}$, (f) Mo, (g) $\mathrm{V}$ and (h) $O$ [50].
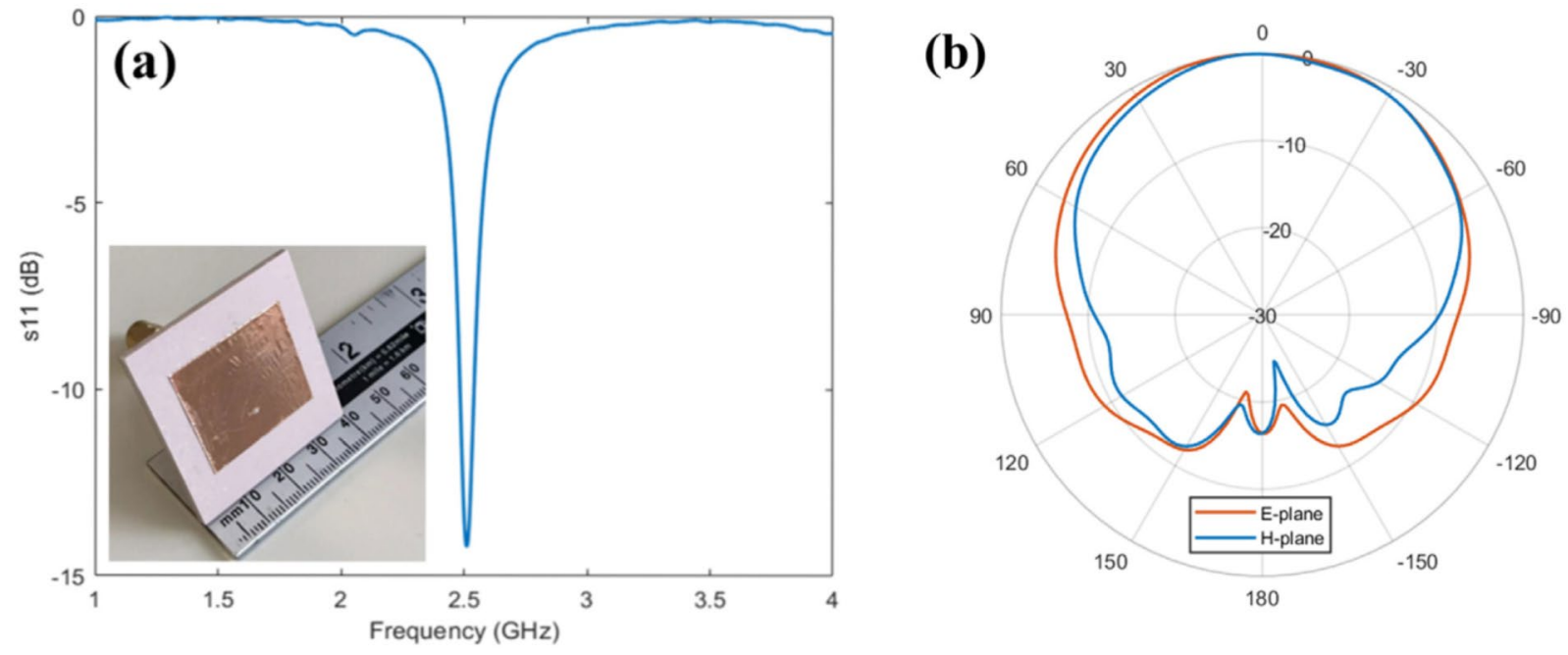

Figure 13: Measured (a) S11 and (b) radiation pattern of the $8 \%$ wt $\%$ CTO-92 wt\%KMO microstrip antenna. The picture of fabricated microstrip antenna is given in the inset of (a) [51].

ventionally sintered counterparts. Humidity sensitivity may well be resolved through a low-cost polymer encapsulation process [112] but how to mitigate against low mechanical strength remains unclear and could limit cold sintering to integrated structures on PCBs which would supply superior handling characteristics.

(5) Many RF devices (antennas, resonators, filters, etc.) have relatively simple geometries (rectangular blocks or cylinders). Further work required to understand and control the cold-sintered process in more complex pressed or moulded shapes. In principle however, if a shape can be uniaxially pressed prior to conventional sintering, then it is feasible that it can fabricated by cold sintering.

\section{Acknowledgments}

This work was supported by the Engineering and Physical Sciences Research Council (EPSRC) funded through Grant Nos. EP/L017563/1 and EP/N010493/1; Henry Royce Institute for Advanced Materials funded through EPSRC Grants EP/ R00661X/1, EP/S019367/1, EP/P02470X/1 and EP/P025285/1. 

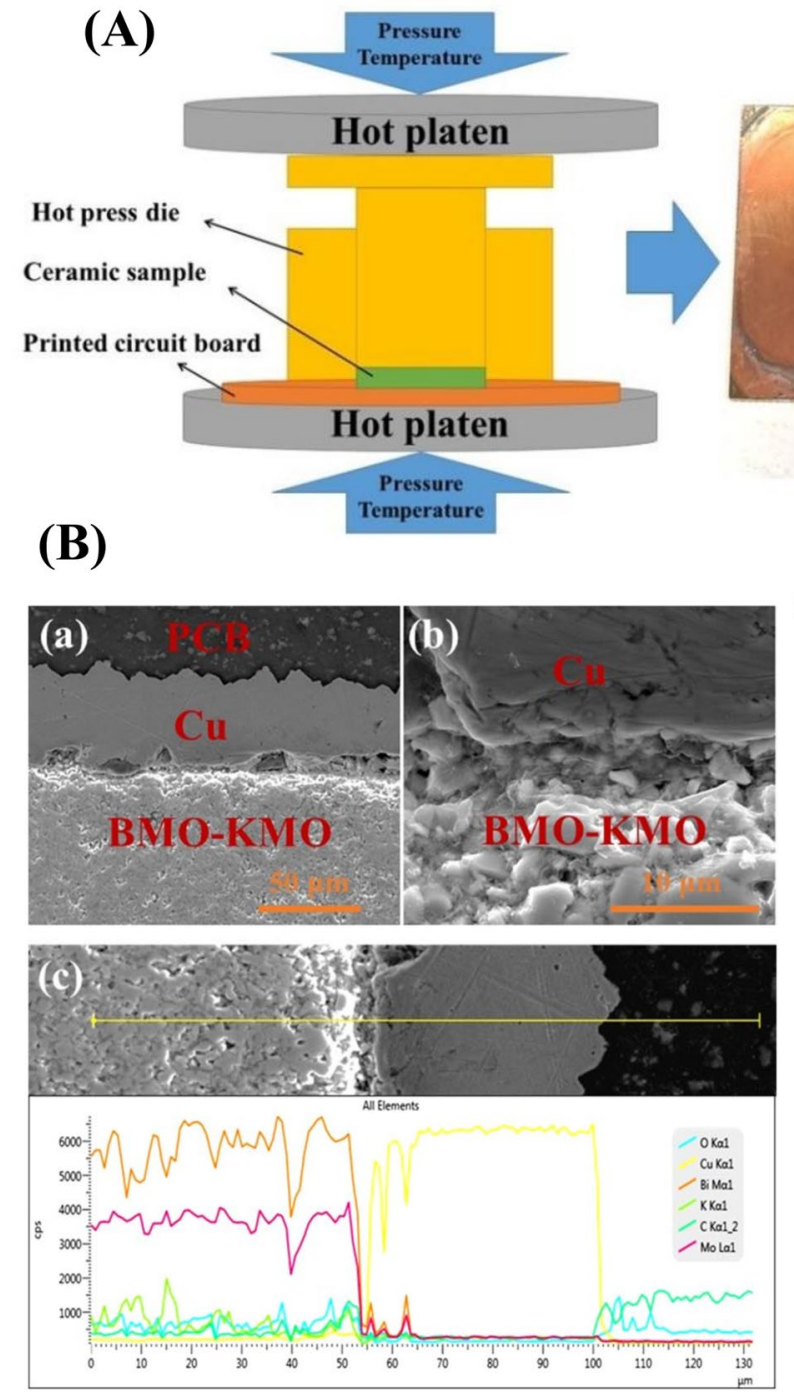
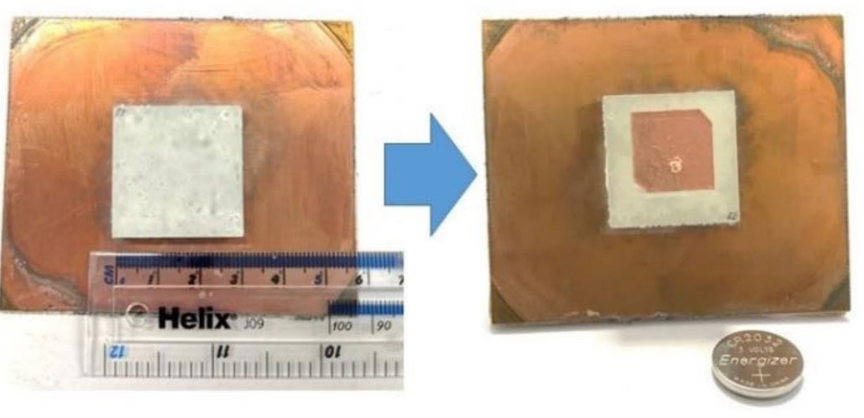

(C)

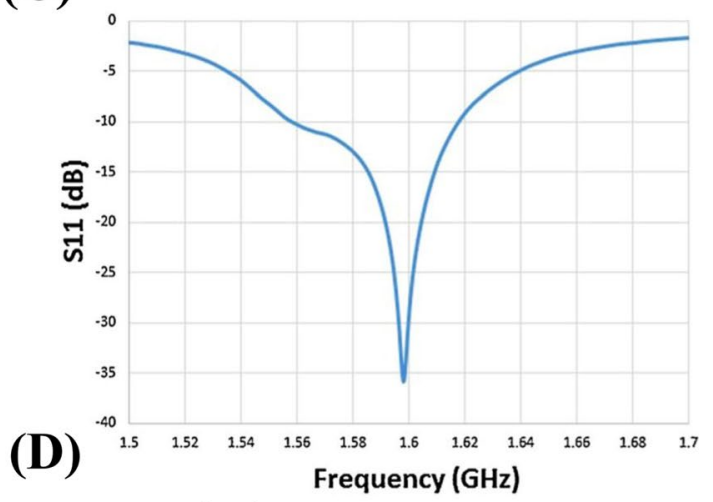

\begin{tabular}{lll}
\hline Parameters & BeiDou & GPS/Galileo \\
\hline Frequency & $1561 \mathrm{MHz}$ & $1575 \mathrm{MHz}$ \\
Polarization & RHCP & RHCP \\
Gain & $5.7 \mathrm{dBic}$ & $5.8 \mathrm{dBic}$ \\
Directivity & $6.4 \mathrm{dBic}$ & $6.4 \mathrm{dBic}$ \\
Total efficiency & $87 \%$ & $88 \%$ \\
Axial ratio & $2.1 \mathrm{~dB}$ & $1.9 \mathrm{~dB}$ \\
\hline
\end{tabular}

Figure 14: (A) Schematic diagram of cold sintering ceramic substrate for antennas; (B) SEM images and EDS elemental line-scans of a cross section of cold-sintered BMO-KMO on a Cu-metallized PCB; (C) measured S11 curve of the antenna and (D) measured antenna performance of the fabricated ceramic antenna at two frequency bands [52].

\section{Supplementary information}

The online version contains supplementary material available at https://doi.org/10.1557/s43578-020-00029-w.

\section{Open access}

This article is licensed under a Creative Commons Attribution 4.0 International License, which permits use, sharing, adaptation, distribution and reproduction in any medium or format, as long as you give appropriate credit to the original author(s) and the source, provide a link to the Creative Commons licence, and indicate if changes were made. The images or other third party material in this article are included in the article's Creative Commons licence, unless indicated otherwise in a credit line to the material. If material is not included in the article's Creative Commons licence and your intended use is not permitted by statutory regulation or exceeds the permitted use, you will need to obtain permission directly from the copyright holder. To view a copy of this licence, visit http://creativeco mmons.org/licenses/by/4.0/.

\section{References}

1. I.M. Reaney, D. Iddles, Microwave dielectric ceramics for resonators and filters in mobile phone networks. J. Am. Ceram. Soc. 89(7), 2063 (2006)

2. M. Sebastian, R. Ubic, H. Jantunen, Low-loss dielectric ceramic materials and their properties. Int. Mater. Rev. 60(7), 392 (2015)

3. J. Guo, A.L. Baker, H. Guo, M. Lanagan, C.A. Randall, Cold sintering process: a new era for ceramic packaging and microwave device development. J. Am. Ceram. Soc. 100(2), 669 (2017) 
4. R. Cava, Dielectric materials for applications in microwave communications. J. Mater. Chem. 11(1), 54 (2001)

5. H. Ouchi, S. Kawashima, Dielectric ceramics for microwave application. Jpn. J. Appl. Phys. 24(S2), 60 (1985)

6. I.M. Reaney, E.L. Colla, N. Setter, Dielectric and structural characteristics of $\mathrm{Ba}$-and $\mathrm{Sr}$-based complex perovskites as a function of tolerance factor. Jpn. J. Appl. Phys. 33(7R), 3984 (1994)

7. E. Colla, I. Reaney, N. Setter, Effect of structural changes in complex perovskites on the temperature coefficient of the relative permittivity. J. Appl. Phys. 74(5), 3414 (1993)

8. R. Ubic, I. Reaney, W. Lee, Microwave dielectric solid-solution phase in system $\mathrm{BaO}-\mathrm{Ln}_{2} \mathrm{O}_{3}-\mathrm{TiO}_{2}$ ( $\mathrm{Ln}=$ lanthanide cation). Int. Mater. Rev. 43(5), 205 (1998)

9. R.C. Pullar, The synthesis, properties, and applications of columbite niobates (M2+ Nb2O6): a critical review. J. Am. Ceram. Soc. 92(3), 563 (2009)

10. L.X. Pang, D. Zhou, Modification of NdNbO4 microwave dielectric ceramic by Bi substitutions. J. Am. Ceram. Soc. 102(5), 2278 (2019)

11. Z. Tan, K. Song, H.B. Bafrooei, B. Liu, J. Wu, J. Xu, H. Lin, D. Wang, The effects of $\mathrm{TiO}_{2}$ addition on microwave dielectric properties of $\mathrm{Y}_{3} \mathrm{MgAl}_{3} \mathrm{SiO}_{12}$ ceramic for $5 \mathrm{G}$ application. Ceram. Int. 46(10), 15665 (2020)

12. Q. Lin, K. Song, B. Liu, H.B. Bafrooei, D. Zhou, W. Su, F. Shi, D. Wang, H. Lin, I.M. Reaney, Vibrational spectroscopy and microwave dielectric properties of $\mathrm{AY}_{2} \mathrm{Si}_{3} \mathrm{O}_{10}(\mathrm{~A}=\mathrm{Sr}, \mathrm{Ba})$ ceramics for 5G applications. Ceram. Int. 46(1), 1171 (2020)

13. Z. Song, K. Song, B. Liu, P. Zheng, H. BarzegarBafrooei, W. Su, H. Lin, F. Shi, D. Wang, I. Reaney, Temperature-dependent dielectric and Raman spectra and microwave dielectric properties of gehlenite-type $\mathrm{Ca}_{2} \mathrm{Al}_{2} \mathrm{SiO}_{7}$ ceramics. Int. J. Appl. Ceram. Technol. 17(2), 771 (2020)

14. T. Ibn-Mohammed, C.A. Randall, K.B. Mustapha, J. Guo, J. Walker, S. Berbano, S.C.L. Koh, D. Wang, D.C. Sinclair, I.M. Reaney, Decarbonising ceramic manufacturing: a techno-economic analysis of energy efficient sintering technologies in the functional materials sector. J. Eur. Ceram. Soc. 39(16), 5213 (2019)

15. M.T. Sebastian, H. Wang, H. Jantunen, Low temperature cofired ceramics with ultra-low sintering temperature: a review. Curr. Opin. Solid State Mater. Sci. 20(3), 151 (2016)

16. M.T. Sebastian, H. Jantunen, Low loss dielectric materials for LTCC applications: a review. Int. Mater. Rev. 53(2), 57 (2008)

17. J. Zhou, Towards rational design of low-temperature co-fired ceramic (LTCC) materials. J. Adv. Ceram. 1(2), 89 (2012)

18. H. Jantunen, T. Kangasvieri, J. Vähäkangas, S. Leppävuori, Design aspects of microwave components with LTCC technique. J. Eur. Ceram. Soc. 23(14), 2541 (2003)

19. H. Yu, J. Liu, W. Zhang, S. Zhang, Ultra-low sintering temperature ceramics for LTCC applications: a review. J. Mater. Sci. 26(12), 9414 (2015)
20. D. Zhou, L.X. Pang, D.W. Wang, C. Li, B.B. Jin, I.M. Reaney, High permittivity and low loss microwave dielectrics suitable for $5 \mathrm{G}$ resonators and low temperature co-fired ceramic architecture. J. Mater. Chem. C 5(38), 10094 (2017)

21. H.P. Braun, A. Mehmood, M. Hovhannisyan, H. Zhang, D.S.B. Heidary, C. Randall, M.T. Lanagan, R. Jakoby, I.M. Reaney, M. Letz, Microwave properties and structure of $\mathrm{La}-\mathrm{Ti}-\mathrm{Si}-\mathrm{B}-$ O glass-ceramics for applications in GHz electronics. J. Eur. Ceram. Soc. 37(5), 2137 (2017)

22. H. Yu, K. Ju, K. Wang, A novel glass-ceramic with ultra-low sintering temperature for LTCC application. J. Am. Ceram. Soc. 97(3), 704 (2014)

23. I.J. Induja, M.T. Sebastian, Microwave dielectric properties of $\mathrm{SnO}-\mathrm{SnF}_{2}-\mathrm{P}_{2} \mathrm{O}_{5}$ glass and its composite with alumina for ULTCC applications. J. Am. Ceram. Soc. 100(6), 2632 (2017)

24. M. Valant, D. Suvorov, Glass-free low-temperature cofired ceramics: calcium germanates, silicates and tellurates. J. Am. Ceram. Soc. 24(6), 1715 (2004)

25. M. Udovic, M. Valant, D. Suvorov, Dielectric characterisation of ceramics from the $\mathrm{TiO}_{2}-\mathrm{TeO}_{2}$ system. J. Eur. Ceram. Soc. 21(10-11), 1735 (2001)

26. R. Gheisari, H. Chamberlain, G. Chi-Tangyie, S. Zhang, A. Goulas, C.-K. Lee, T. Whittaker, D. Wang, A. Ketharam, A. Ghosh, Multi-material additive manufacturing of low sintering temperature $\mathrm{Bi}_{2} \mathrm{Mo}_{2} \mathrm{O}_{9}$ ceramics with $\mathrm{Ag}$ floating electrodes by selective laser burnout. Virt. Phys. Prototyping J. 15(2), 133 (2020)

27. D. Zhou, L.-X. Pang, D.-W. Wang, H.-H. Guo, F. Yang, Z.-M. Qi, C. Li, B.-B. Jin, I.M. Reaney, Crystal structure, impedance and broadband dielectric spectra of ordered scheelite-structured $\mathrm{Bi}$ $\left(\mathrm{Sc}_{1 / 3} \mathrm{Mo}_{2 / 3}\right) \mathrm{O}_{4}$ ceramic. J. Eur. Ceram. Soc. 38(4), 1556 (2018)

28. L.X. Pang, D. Zhou, D.W. Wang, J.X. Zhao, W.G. Liu, Z.X. Yue, I.M. Reaney, Temperature stable microwave dielectrics ceramics with ultra-low sintering temperature. J. Am. Ceram. Soc. 101(5), 1806 (2018)

29. D. Zhou, J. Li, L.-X. Pang, D.-W. Wang, I.M. Reaney, Reaney: novel water insoluble $\left(\mathrm{Na}_{\mathrm{x}} \mathrm{Ag}_{2-\mathrm{x}}\right) \mathrm{MoO}_{4}(0 \leq \mathrm{x} \leq 2)$ microwave dielectric ceramics with spinel structure sintered at 410 degrees. J. Mater. Chem. C 5(24), 6086 (2017)

30. S.-Z. Hao, D. Zhou, F. Hussain, W.-F. Liu, J.-Z. Su, D.-W. Wang, Q.-P. Wang, Z.-M. Qi, C. Singh, S. Trukhanov, Structure, spectral analysis and microwave dielectric properties of novel $\mathrm{x}$ $(\mathrm{NaBi})_{0.5} \mathrm{MoO}_{4^{-}}(1-\mathrm{x}) \mathrm{Bi}_{2 / 3} \mathrm{MoO}_{4}(\mathrm{x}=0.2 \sim 0.8)$ ceramics with low sintering temperatures. J. Eur. Ceram. Soc. 40(10), 3569 (2020)

31. A. Goulas, G. Chi-Tangyie, D. Wang, S. Zhang, A. Ketharam, B. Vaidhyanathan, I.M. Reaney, D.A. Cadman, W.G. Whittow, J.Y.C. Vardaxoglou, Additively manufactured ultra-low sintering temperature, low loss $\mathrm{Ag}_{2} \mathrm{Mo}_{2} \mathrm{O}_{7}$ ceramic substrates. J. Eur. Ceram. Soc. 41, 394-401 (2020)

32. H.H. Guo, D. Zhou, W.F. Liu, L.X. Pang, D.W. Wang, J.Z. Su, Z.M. Qi, Microwave dielectric properties of temperature-stable 
zircon-type (Bi, Ce)VO4 solid solution ceramics. J. Am. Ceram. Soc. 103(1), 423 (2020)

33. D. Zhou, L.-X. Pang, D.-W. Wang, I.M. Reaney, $\mathrm{BiVO}_{4}$ based high k microwave dielectric materials: a review. J. Mater. Chem. C 6(35), 9290 (2018)

34. D. Zhou, D. Guo, W.-B. Li, L.-X. Pang, X. Yao, D.-W. Wang, I.M. Reaney, Novel temperature stable high- $\varepsilon_{\mathrm{r}}$ microwave dielectrics in the $\mathrm{Bi}_{2} \mathrm{O}_{3}-\mathrm{TiO}_{2}-\mathrm{V}_{2} \mathrm{O}_{5}$ system. J. Mater. Chem. C 4(23), 5357 (2016)

35. J.L. Di Zhou, L.-X. Pang, G.-H. Chen, Z.-M. Qi, D.-W. Wang, I.M. Reaney, Crystal structure, infrared spectra, and microwave dielectric properties of temperature-stable zircon-type (Y, $\mathrm{Bi})$ VO4 solid-solution ceramics. ACS Omega 1(5), 963 (2016)

36. H.-D. Xie, H.-H. Xi, C. Chen, D. Zhou, Microwave dielectric properties of two low temperature sintering ceramics in the $\mathrm{PbO}-\mathrm{WO}_{3}$ binary system. Ceram. Int. 41(8), 10287 (2015)

37. D. Zhou, C.A. Randall, L.X. Pang, H. Wang, J. Guo, G.Q. Zhang, X.G. Wu, L. Shui, X. Yao, Microwave dielectric properties of Li2WO4 ceramic with ultra-low sintering temperature. J. Am. Ceram. Soc. 94(2), 348 (2011)

38. J. Guo, D. Zhou, S.L. Zou, H. Wang, L.X. Pang, X. Yao, Microwave dielectric ceramics $\mathrm{Li}_{2} \mathrm{MO}_{4}-\mathrm{TiO}_{2}(\mathrm{M}=\mathrm{Mo}, \mathrm{W})$ with low sintering temperatures. J. Am. Ceram. Soc. 97(6), 1819 (2014)

39. X. Chen, W. Zhang, B. Zalinska, I. Sterianou, S. Bai, I.M. Reaney, Low sintering temperature microwave dielectric ceramics and composites based on $\mathrm{Bi}_{2} \mathrm{O}_{3}-\mathrm{B}_{2} \mathrm{O}_{3}$. J. Am. Ceram. Soc. 95(10), 3207 (2012)

40. D. Zhou, L.-X. Pang, D.-W. Wang, Z.-M. Qi, I.M. Reaney, High quality factor, ultralow sintering temperature $\mathrm{Li}_{6} \mathrm{~B}_{4} \mathrm{O}_{9}$ microwave dielectric ceramics with ultralow density for antenna substrates. ACS Sustain. Chem. Eng. 6(8), 11138 (2018)

41. X.G. Wu, H. Wang, Y.H. Chen, D. Zhou, Synthesis and microwave dielectric properties of $\mathrm{Zn}_{3} \mathrm{~B}_{2} \mathrm{O}_{6}$ ceramics for substrate application. J. Am. Ceram. Soc. 95(6), 1793 (2012)

42. J. Guo, H. Guo, A.L. Baker, M.T. Lanagan, E.R. Kupp, G.L. Messing, C.A. Randall, Cold sintering: a paradigm shift for processing and integration of ceramics. Angew. Chem. Int. Ed. Engl. 55(38), 11457 (2016)

43. J. Guo, S.S. Berbano, H. Guo, A.L. Baker, M.T. Lanagan, C.A. Randall, Cold sintering process of composites: bridging the processing temperature gap of ceramic and polymer materials. Adv. Funct. Mater. 26(39), 7115 (2016)

44. J.-P. Maria, X. Kang, R.D. Floyd, E.C. Dickey, H. Guo, J. Guo, A. Baker, S. Funihashi, C.A. Randall, Cold sintering: current status and prospects. J. Mater. Res. 32(17), 3205 (2017)

45. J. Guo, X. Zhao, T. Herisson De Beauvoir, J.-H. Seo, S.S. Berbano, A.L. Baker, C. Azina, C.A. Randall, Recent progress in applications of the cold sintering process for ceramic-polymer composites. Adv. Funct. Mater. 28(39), 1801724 (2018)
46. Y. Liu, Q. Sun, D. Wang, K. Adair, J. Liang, X. Sun, Development of the cold sintering process and its application in solid-state lithium batteries. J. Power Sources. 393, 193 (2018)

47. J. Guo, R. Floyd, S. Lowum, J.-P. Maria, T. Herisson de Beauvoir, J.-H. Seo, C.A. Randall, Cold sintering: progress, challenges, and future opportunities. Annu. Rev. Mater. Res. 49(1), 275 (2019)

48. T. Yu, J. Cheng, L. Li, B. Sun, X. Bao, H. Zhang, Current understanding and applications of the cold sintering process. Front. Chem. Sci. Eng. 13(4), 654 (2019)

49. S. Grasso, M. Biesuz, L. Zoli, G. Taveri, A.I. Duff, D. Ke, A. Jiang, M.J. Reece, A review of cold sintering processes. Adv. Appl. Ceram. 119(3), 115 (2020)

50. D. Wang, D. Zhou, K. Song, A. Feteira, C.A. Randall, I.M. Reaney, Cold-sintered C0G multilayer ceramic capacitors. Adv. Electron. Mater. 5(7), 1900025 (2019)

51. D. Wang, S. Zhang, G. Wang, Y. Vardaxoglou, W. Whittow,

D. Cadman, D. Zhou, K. Song, I.M. Reaney, Cold sintered $\mathrm{CaTiO}_{3}-\mathrm{K}_{2} \mathrm{MoO}_{4}$ microwave dielectric ceramics for integrated microstrip patch antennas. Appl. Mater. Today 18, 100519 (2020)

52. D. Wang, B. Siame, S. Zhang, G. Wang, X. Ju, J. Li, Z. Lu, Y. Vardaxoglou, W. Whittow, D. Cadman, S. Sun, D. Zhou, K. Song, I.M. Reaney, Direct integration of cold sintered, temperaturestable $\mathrm{Bi}_{2} \mathrm{Mo}_{2} \mathrm{O}_{9}-\mathrm{K}_{2} \mathrm{MoO}_{4}$ ceramics on printed circuit boards for satellite navigation antennas. J. Eur. Ceram. Soc. 40(12), 4029 (2020)

53. A. Baker, H. Guo, J. Guo, C. Randall, D.J. Green, Utilizing the cold sintering process for flexible-printable electroceramic device fabrication. J. Am. Ceram. Soc. 99(10), 3202 (2016)

54. J.-P. Ma, X.-M. Chen, W.-Q. Ouyang, J. Wang, H. Li, J.-L. Fang, Microstructure, dielectric, and energy storage properties of $\mathrm{BaTiO}_{3}$ ceramics prepared via cold sintering. Ceram. Int. 44(4), 4436 (2018)

55. K. Tsuji, A. Ndayishimiye, S. Lowum, R. Floyd, K. Wang, M. Wetherington, J.-P. Maria, C.A. Randall, Single step densification of high permittivity $\mathrm{BaTiO}_{3}$ ceramics at $300{ }^{\circ} \mathrm{C}$. J. Eur. Ceram. Soc. 40(4), 1280 (2020)

56. H. Guo, A. Baker, J. Guo, C.A. Randall, D. Johnson, Cold sintering process: a novel technique for low-temperature ceramic processing of ferroelectrics. J. Am. Ceram. Soc. 99(11), 3489 (2016)

57. H. Guo, A. Baker, J. Guo, C.A. Randall, Protocol for ultralowtemperature ceramic sintering: an integration of nanotechnology and the cold sintering process. ACS Nano 10(11), 10606 (2016)

58. H. Guo, J. Guo, A. Baker, C.A. Randall, Hydrothermal-assisted cold sintering process: a new guidance for low-temperature ceramic sintering. ACS Appl. Mater. Interfaces. 8(32), 20909 (2016) 
59. D. Wang, H. Guo, C.S. Morandi, C.A. Randall, S. TrolierMcKinstry, Cold sintering and electrical characterization of lead zirconate titanate piezoelectric ceramics. APL Mater. 6(1), 016101 (2018)

60. M. Chi, W. Ma, J. Guo, J. Wu, T. Li, S. Wang, P. Zhang, Effect of $\mathrm{NaCl}$ on the microstructure and electrical properties of prepared by cold sintering process. J. Mater. Sci. 30(24), 2143521443 (2019)

61. H. Huang, J. Tang, J. Liu, Preparation of $\mathrm{Na}_{0.5} \mathrm{Bi}_{0.5} \mathrm{TiO}_{3}$ ceramics by hydrothermal-assisted cold sintering. Ceram. Int. 45(6), 6753 (2019)

62. J. Ma, H. Li, H. Wang, C. Lin, X. Wu, T. Lin, X. Zheng, X. Yu, Composition, microstructure and electrical properties of ceramics fabricated by cold sintering assisted sintering. J. Eur. Ceram. Soc. 39(4), 986 (2019)

63. M. Nelo, T. Siponkoski, H. Kähäri, K. Kordas, J. Juuti, H. Jantunen, Upside - down composites: fabricating piezoceramics at room temperature. J. Eur. Ceram. Soc. 39(11), 3301 (2019)

64. S. Funahashi, H. Guo, J. Guo, A.L. Baker, K. Wang, K. Shiratsuyu, C.A. Randall, Cold sintering and co-firing of a multilayer device with thermoelectric materials. J. Am. Ceram. Soc. 100(8), 3488 (2017)

65. S. Funahashi, J. Guo, H. Guo, K. Wang, A.L. Baker, K. Shiratsuyu, C.A. Randall, Demonstration of the cold sintering process study for the densification and grain growth of $\mathrm{ZnO}$ ceramics. J. Am. Ceram. Soc. 100(2), 546 (2017)

66. J. Guo, H. Guo, D.S.B. Heidary, S. Funahashi, C.A. Randall, Semiconducting properties of cold sintered $\mathrm{V}_{2} \mathrm{O}_{5}$ ceramics and Co-sintered $\mathrm{V}_{2} \mathrm{O}_{5}$-PEDOT:PSS composites. J. Eur. Ceram. Soc. 37(4), 1529 (2017)

67. J. Guo, B. Legum, B. Anasori, K. Wang, P. Lelyukh, Y. Gogotsi, C.A. Randall, Cold sintered ceramic nanocomposites of 2D MXene and zinc oxide. Adv. Mater. 30(32), e1801846 (2018)

68. D.S.B. Heidary, J. Guo, J.-H. Seo, H. Guo, R. Rajagopalan, C.A. Randall, Microstructures and electrical properties of $\mathrm{V}_{2} \mathrm{O}_{5}$ and carbon-nanofiber composites fabricated by cold sintering process. Jpn. J. Appl. Phys. 57(2), 25702 (2018)

69. S.H. Bang, K. Tsuji, A. Ndayishimiye, S. Dursun, J.H. Seo, S. Otieno, C.A. Randall, Toward a size scale-up cold sintering process at reduced uniaxial pressure. J. Am. Ceram. Soc. 103(4), 2322 (2020)

70. M.Y. Sengul, J. Guo, C.A. Randall, A.C.T. van Duin, Watermediated surface diffusion mechanism enables the cold sintering process: a combined computational and experimental study. Angew Chem. Int. Ed. Engl. 58(36), 12420 (2019)

71. S.S. Berbano, J. Guo, H. Guo, M.T. Lanagan, C.A. Randall, Randall: cold sintering process of $\mathrm{Li}_{1.5} \mathrm{Al}_{0.5} \mathrm{Ge}_{1.5}\left(\mathrm{PO}_{4}\right)_{3}$ solid electrolyte. J. Am. Ceram. Soc. 100(5), 2123 (2017)

72. H. Leng, J. Huang, J. Nie, J. Luo, Cold sintering and ionic conductivities of solid electrolytes. J. Power Sources. 391, 170 (2018)
73. W. Lee, C.K. Lyon, J.H. Seo, R. Lopez-Hallman, Y. Leng, C.Y. Wang, M.A. Hickner, C.A. Randall, E.D. Gomez, Ceramic-salt composite electrolytes from cold sintering. Adv. Funct. Mater. 29(20), 1807812 (2019)

74. H. Nakaya, M. Iwasaki, T.H. de Beauvoir, C.A. Randall, Applying cold sintering process to a proton electrolyte material: $\mathrm{CsH}_{2} \mathrm{PO}_{4}$. J. Eur. Ceram. Soc. 39(2-3), 396 (2019)

75. T.H. Zaengle, A. Ndayishimiye, K. Tsuji, Z. Fan, S.H. Bang, J. Perini, S.T. Misture, C.A. Randall, Single-step densification of nanocrystalline $\mathrm{CeO} 2$ by the cold sintering process. J. Am. Ceram. Soc. 103(5), 2979 (2020)

76. J.-H. Seo, J. Guo, H. Guo, K. Verlinde, D.S.B. Heidary, R. Rajagopalan, C.A. Randall, Cold sintering of a Li-ion cathode: $\mathrm{LiFePO}_{4}$-composite with high volumetric capacity. Ceram. Int. 43(17), 15370 (2017)

77. J.-H. Seo, K. Verlinde, J. Guo, D.S.B. Heidary, R. Rajagopalan, T.E. Mallouk, C.A. Randall, Cold sintering approach to fabrication of high rate performance binderless $\mathrm{LiFePO}_{4}$ cathode with high volumetric capacity. Scripta Materialia. 146, 267 (2018)

78. H. Guo, T.J.M. Bayer, J. Guo, A. Baker, C.A. Randall, Cold sintering process for $8 \mathrm{~mol} \% \mathrm{Y}_{2} \mathrm{O}_{3}$-stabilized $\mathrm{ZrO}_{2}$ ceramics. J. Eur. Ceram. Soc. 37(5), 2303 (2017)

79. H. Guo, T.J.M. Bayer, J. Guo, A. Baker, C.A. Randall, Current progress and perspectives of applying cold sintering process to $\mathrm{ZrO}_{2}$-based ceramics. Scripta Materialia. 136, 141 (2017)

80. H. Guo, J. Guo, A. Baker, C.A. Randall, Cold sintering process for $\mathrm{ZrO}_{2}$-based ceramics: significantly enhanced densification evolution in yttria-doped $\mathrm{ZrO}_{2}$. J. Am. Ceram. Soc. 100(2), 491 (2017)

81. D. Zhou, L.-X. Pang, D.-W. Wang, I.M. Reaney, Novel waterassisting low firing $\mathrm{MoO}_{3}$ microwave dielectric ceramics. J. Eur. Ceram. Soc. 39(7), 2374 (2019)

82. J. Song, G. Zhu, H. Xu, R. Yin, Y. Zhao, X. Zhang, D. Yan, S. Long, T. Wei, Preparation of high-density $\mathrm{Bi}_{2} \mathrm{O}_{3}$ ceramics by low temperature sintering. J. Mater. Sci. 31(7), 5214 (2020)

83. C. Zhong, Y. Deng, W. Hu, J. Qiao, L. Zhang, J. Zhang, A review of electrolyte materials and compositions for electrochemical supercapacitors. Chem. Soc. Rev. 44(21), 7484 (2015)

84. M.-J. Pan, C.A. Randall, A brief introduction to ceramic capacitors. IEEE Electr. Insulat. Mag. 26(3), 44 (2010)

85. C.-H. Hong, H.-P. Kim, B.-Y. Choi, H.-S. Han, J.S. Son, C.W. Ahn, W. Jo, Lead-free piezoceramics-where to move on? J. Materiom. 2(1), 1 (2016)

86. Y. Zhang, Y.-J. Heo, M. Park, S.-J. Park, Recent advances in organic thermoelectric materials: principle mechanisms and emerging carbon-based green energy materials. Polymers 11(1), 167 (2019)

87. W.D. Kingery, H.K. Bowen, D.R. Uhlmann, Introduction to Ceramics (Wiley, Hoboken, 1976)

88. X. Zhao, J. Guo, K. Wang, T. Beauvoir, B. Li, C.A. Randall: Introducing a $\mathrm{ZnO}-\mathrm{PTFE}$ (polymer) nanocomposite varistor via the 
cold sintering process. Adv. Eng. Mater. https://doi.org/10.1002/ adem.201700902 (2018)

89. E.M. Gutman: Mechanochemistry of solid surfaces (World Scientific Publishing Company, City, 1994)

90. W. Kingery, J. Woulbroun, F. Charvat, Effects of applied pressure on densification during sintering in the presence of a liquid phase. J. Am. Ceram. Soc. 46(8), 391 (1963)

91. Y. Cai, B.-M. Zhang Newby, Marangoni flow-induced selfassembly of hexagonal and stripelike nanoparticle patterns. J. Am. Chem. Soc. 130(19), 6076 (2008)

92. W.B. Hong, L. Li, M. Cao, X.M. Chen, Plastic deformation and effects of water in room-temperature cold sintering of $\mathrm{NaCl}$ microwave dielectric ceramics. J. Am. Ceram. Soc. 101(9), 4038 (2018)

93. H. Kähäri, M. Teirikangas, J. Juuti, H. Jantunen, N. Alford, Dielectric properties of lithium molybdate ceramic fabricated at room temperature. J. Am. Ceram. Soc. 97(11), 3378 (2014)

94. P. Atkins, J. De Paula, Elements of Physical Chemistry (Oxford University Press, Oxford, 2013)

95. R. Fernandez-Prini, Le Chatelier's principle and the prediction of the effect of temperature on solubilities. J. Chem. Educ. 59(7), 550 (1982)

96. M.M. Renfew: NIOSH Pocket guide to chemical hazards (US Department of Health and Human Services-National Institute for Occupational Safety and Health), (ACS Publications, City, 1991)

97. G. Taveri, S. Grasso, F. Gucci, J. Toušek, I. Dlouhy, Bio-inspired hydro-pressure consolidation of silica. Adv. Funct. Mater. 28(48), 1805794 (2018)

98. H. Kähäri, M. Teirikangas, J. Juuti, H. Jantunen, N. Alford, Improvements and modifications to room-temperature fabrication method for dielectric $\mathrm{Li}_{2} \mathrm{MoO}_{4}$ ceramics. J. Am. Ceram. Soc. 98(3), 687 (2015)

99. L. Li, W.B. Hong, S. Yang, H. Yan, X.M. Chen, Effects of water content during cold sintering process of $\mathrm{NaCl}$ ceramics. J. Alloys Compd. 787, 352 (2019)

100. D. Wang, D. Zhou, S. Zhang, Y. Vardaxoglou, W.G. Whittow, D. Cadman, I.M. Reaney, Cold-sintered temperature stable $\mathrm{Na}_{0.5} \mathrm{Bi}_{0.5} \mathrm{MoO}_{4}-\mathrm{Li}_{2} \mathrm{MoO}_{4}$ microwave composite ceramics. ACS Sustain. Chem. Eng. 6(2), 2438 (2018)

101. D. Wang, S. Zhang, D. Zhou, K. Song, A. Feteira, Y. Vardaxoglou, W. Whittow, D. Cadman, I.M. Reaney, Temperature stable cold sintered $\left(\mathrm{Bi}_{0.95} \mathrm{Li}_{0.05}\right)\left(\mathrm{V}_{0.9} \mathrm{Mo}_{0.1}\right) \mathrm{O}_{4}-\mathrm{Na}_{2} \mathrm{Mo}_{2} \mathrm{O}_{7}$ microwave dielectric composites. Materials 12, 9 (2019)
102. D. Wang, J. Chen, G. Wang, Z. Lu, S. Sun, J. Li, J. Jiang, D. Zhou, K. Song, I.M. Reaney, Cold sintered LiMgPO4 based composites for low temperature co-fired ceramic (LTCC) applications. J. Am. Ceram. Soc. 103, 6237 (2020)

103. H. Kähäri, M. Teirikangas, J. Juuti, H. Jantunen, Room-temperature fabrication of microwave dielectric $\mathrm{Li}_{2} \mathrm{MoO}_{4}-\mathrm{TiO}_{2}$ composite ceramics. Ceram. Int. 42(9), 11442 (2016)

104. I.J. Induja, M.T. Sebastian, Microwave dielectric properties of mineral sillimanite obtained by conventional and cold sintering process. J. Eur. Ceram. Soc. 37(5), 2143 (2017)

105. M. Väätäjä, H. Kähäri, J. Juuti, H. Jantunen, $\mathrm{Li}_{2} \mathrm{MoO}_{4}$-based composite ceramics fabricated from temperature- and atmospheresensitive $\mathrm{MnZn}$ ferrite at room temperature. J. Am. Ceram. Soc. 100(8), 3626 (2017)

106. S.S. Faouri, A. Mostaed, J.S. Dean, D. Wang, D.C. Sinclair, S. Zhang, W.G. Whittow, Y. Vardaxoglou, I.M. Reaney, High quality factor cold sintered $\mathrm{Li}_{2} \mathrm{MoO}_{4}-\mathrm{BaFe}_{12} \mathrm{O}_{19}$ composites for microwave applications. Acta Materialia. 166, 202 (2019)

107. Y. Ji, K. Song, X. Luo, B. Liu, H. Barzegar Bafrooei, D. Wang, Microwave dielectric properties of composite ceramics fabricated by cold sintering process. Front. Mater. 6, 256 (2019)

108. S.N.A. Rajan, Garnet mineral based composites through cold sintering process: microstructure and dielectric properties. J. Eur. Ceram. Soc. 40(2), 371 (2020)

109. Y. Ji, K. Song, S. Zhang, Z. Lu, G. Wang, L. Li, D. Zhou, D. Wang and I.M. Reaney: Cold sintered, temperature-stable $\mathrm{CaSnSiO}_{5}-\mathrm{K}_{2} \mathrm{MoO}_{4}$ composite microwave ceramics and its prototype microstrip patch antenna Journal of the European Ceramic Society. (2020)

110. W.B. Hong, L. Li, H. Yan, X.M. Chen, Cold sintering and microwave dielectric properties of dense HBO2-II ceramics. J. Am. Ceram. Soc. 102(10), 5934 (2019)

111. B. Liu, L. Li, K.X. Song, M.M. Mao, Z. Lu, G. Wang, L. Li, D. Wang, D. Zhou, A. Feteira and I.M. Reaney: Enhancement of densification and microwave dielectric properties in LiF ceramics via a cold sintering and post-annealing process. J. Eur. Ceram. Soc. (2020)

112. H. Kähäri, P. Ramachandran, J. Juuti, H. Jantunen, Room-temperature-densified $\mathrm{Li}_{2} \mathrm{MoO}_{4}$ ceramic patch antenna and the effect of humidity. Int. J. Appl. Ceram. Technol. 14(1), 50 (2017) 